\title{
Presenilin 1 Mutants Impair the Self-Renewal and Differentiation of Adult Murine Subventricular Zone-Neuronal Progenitors via Cell-Autonomous Mechanisms Involving Notch Signaling
}

\author{
Karthikeyan Veeraraghavalu, ${ }^{1 \star}$ Se Hoon Choi, ${ }^{2 \star}$ Xiaoqiong Zhang, ${ }^{1}$ and Sangram S. Sisodia ${ }^{1,2}$ \\ ${ }^{1}$ Department of Neurobiology and ${ }^{2}$ Committee on Neurobiology, The University of Chicago, Chicago, Illinois 60637
}

\begin{abstract}
The vast majority of pedigrees with familial Alzheimer's disease (FAD) are caused by inheritance of mutations in the PSEN1 1 gene. While genetic ablation studies have revealed a role for presenilin 1 (PS1) in embryonic neurogenesis, little information has emerged regarding the potential effects of FAD-linked PS1 variants on proliferation, self-renewal and differentiation, key events that control cell fate commitment of adult brain neural progenitors (NPCs). We used adult brain subventricular zone (SVZ)-derived NPC cultures transduced with recombinant lentivirus as a means to investigate the effects of various PS1 mutants on self-renewal and differentiation properties. We now show that viral expression of several PS1 mutants in NPCs leads to impaired self-renewal and altered differentiation toward neuronal lineage, in vitro. In line with these observations, diminished constitutive proliferation and steady-state SVZ progenitor pool size was observed in vivo in transgenic mice expressing the PS1 $\triangle \mathrm{E} 9$ variant. Moreover, NPC cultures established from the SVZ of adult mice expressing PS1 $\triangle \mathrm{E} 9$ exhibit reduced self-renewal capacity and premature exit toward neuronal fates. To these findings, we show that both the levels of endogenous Notch/CBF-1-transcriptional activity and transcripts encoding Notch target genes are diminished in SVZ NPCs expressing PS1 $\triangle \mathrm{E} 9$. The deficits in self-renewal and multipotency are restored by expression of Notch1-ICD or a downstream target of the Notch pathway, Hes1. Hence, we argue that a partial reduction in PS-dependent $\gamma$-secretase processing of the Notch, at least in part, accounts for the impairments observed in SVZ NPCs expressing the FAD-linked PS1 $\Delta \mathrm{E} 9$ variant.
\end{abstract}

\section{Introduction}

Alzheimer's disease (AD) is a progressive neurodegenerative disorder of the brain clinically characterized by neuronal loss, deterioration of cognitive function, and deposition of $\beta$-amyloid plaques. Inheritance of autosomal dominant forms of mutant genes encoding presenilin 1 (PS1), presenilin 2 (PS2) and amyloid precursor protein (APP) are the leading cause of familial early onset AD. PS1 is the catalytic component of the multisubunit $\gamma$-secretase complex that is responsible for regulated intramembranous proteolysis of several type I membrane proteins, including Notch-1 and APP (for review, see Sisodia and St George-Hyslop, 2002; De Strooper, 2003). It is well established that mutations in PS1 enhance the ratio of $A \beta 42 / A \beta 40$ peptides liberated from APP, leading to selective deposition of the $A \beta 42$

\footnotetext{
Received Jan. 30, 2010; revised March 27, 2010; accepted April 1, 2010.

This work was supported by National Institutes of Health Grants AG021494 (S.S.S.) and AG027854 (S.S.S.), the Cure Alzheimer's Fund (S.S.S.), the Chicago Institute for Neurosurgery and Neuroresearch (S.S.S.), the Adler Foundation (K.V.), and the Edward H. Levi Fund (S.H.C.). We thank Dr. Vytas Bindokas for expert assistance with microscopy and image analysis.

S.S.S. discloses that he is a paid Consultant of Nociris Inc. and Eisai Research Laboratories Inc., but is not shareholder in any company that is a maker or owner of a Food and Drug Administration-regulated drug or device. ${ }^{*}$ K.V. and S.H.C. contributed equally to this study.

Correspondence should be addressed to Dr. Sangram S. Sisodia, The University of Chicago, Department of Neurobiology, 947 E. $58^{\text {th }}$ Street, AB 308, Chicago IL 60637. E-mail: ssisodia@bsd.uchicago.edu.

DOI:10.1523/JNEUROSCI.0527-10.2010

Copyright $\odot 2010$ the authors $\quad 0270-6474 / 10 / 306903-13 \$ 15.00 / 0$
}

peptides in amyloid plaques (Selkoe, 1998). However, considering the plethora of proteins interacting with PS1 and the multiple signaling pathways regulated by PS1, understanding of the normal function of PS1 remains incomplete. In this vein, while it is clear that one mechanism by which mutant PS1 cause AD is by elevating the ratio of $A \beta 42 / A \beta 40$ peptides, it is increasingly apparent that these PS1 variants have significant effects on synaptic transmission and plasticity (Parent et al., 1999; Zaman et al., 2000) that may compromise learning and memory processes.

PS1 plays a critical role in embryonic and adult neurogenesis. Germ-line ablation of PS1 alleles in mice results in prenatal lethality due to severe deformities that include thinning of embryonic ventricular zone and precocious proliferation of neural progenitor populations leading to reductions in the neurons throughout the cortex (Shen et al., 1997; Handler et al., 2000). Conditional deletion of both PSEN1 and PSEN2 alleles specifically in embryonic NPCs results in massive depletion of NPC population in the developing ventricular zone of the telencephalon (Kim and Shen, 2008). Likewise, significant reduction in progenitor pool size was observed in the SVZ of adult PS1 ${ }^{+/-}$mice brains (Hitoshi et al., 2002). Previous studies of the effects of FAD-linked PS1 mutants on neurogenesis have been limited to adult hippocampus (Wen et al., 2002; Wang et al., 2004; Chevallier et al., 2005) leaving the effects of PS1 mutations on adult SVZ neural progenitor cell biology unexplored. In this study, we show that the self-renewal and differentiation of virally transduced, cul- 
tured postnatal SVZ progenitors that express different FADlinked PS1 mutants is impaired. These perturbations are recapitulated in a transgenic mouse model that express exon 9 deleted FAD-linked PS1 variant. Finally, we demonstrate that the impairments in NPC self-renewal or differentiation are attributable to impairments in Notch signaling.

\section{Materials and Methods}

Animals. Transgenic mice expressing human wild-type PS1 (PS1hWT) [line S8-4 (Thinakaran et al., 1996)] or FAD-linked human PS1 $\Delta$ E9 [line S9 (Lee et al., 1997)] were used. All mice are heterozygous for the transgene. Background strain for these mice are $[\mathrm{C} 3 \mathrm{H} / \mathrm{HeJ} \times \mathrm{C} 57 \mathrm{BL} / 6 \mathrm{~J} \mathrm{~F} 3] \times$ C57BL/6J n1 (Lee et al., 1997). Animal experiments were conducted in accordance with institutional and National Institutes of Health guidelines.

BrdU labeling and immunohistochemistry. To quantify SVZ proliferation, mice received a single injection of $50 \mathrm{mg} / \mathrm{kg} \mathrm{BrdU}$ (Sigma) and were killed $2 \mathrm{~h}$ after BrdU injection. The mice were deeply anesthetized with a mixture of ketamine and xylazine, and perfused transcardially with $4 \%$ paraformaldehyde in cold $0.1 \mathrm{~m}$ phosphate buffer, $\mathrm{pH} 7.4$, after $0.9 \% \mathrm{NaCl}$. The brains were postfixed overnight and then transferred into $30 \%$ sucrose and kept there until they sank. Coronal sections ( 40 $\mu \mathrm{m})$ were cut from a dry-ice-cooled block on a sliding microtome (Leica) and were stored at $-20^{\circ} \mathrm{C}$ in a cryoprotective buffer containing $28 \%$ ethylene glycol, $23 \%$ glycerin and $0.05 \mathrm{M}$ phosphate buffer until the sections were processed for immunohistochemistry.

For BrdU immunofluorescence staining, every sixth section $(240 \mu \mathrm{m}$ apart) was used and the slices were first treated as follows to denature DNAs: $2 \mathrm{~h}$ incubation in the $50 \%$ formamide/ $2 \times$ SSC $(0.3 \mathrm{M} \mathrm{NaCl}$ and $0.03 \mathrm{M}$ Sodium citrate) at $65^{\circ} \mathrm{C}, 15 \mathrm{~min}$ rinse in $2 \times \mathrm{SSC}, 30 \mathrm{~min}$ incubation in $2 \mathrm{~N} \mathrm{HCl}$ at $37^{\circ} \mathrm{C}$. Acid was neutralized by rinsing the sections for $10 \mathrm{~min}$ in $0.1 \mathrm{~m}$ boric acid, $\mathrm{pH} 8.5$, followed by several washes in Trisbuffered saline (TBS, pH 7.5). The sections were incubated in TBS containing $0.25 \%$ Triton $\mathrm{X}-100$ (TBS+), blocked with TBS containing $0.25 \%$ Triton X-100/5\% donkey serum (TBS ++ ) then incubated with rat anti-BrdU (1:100, Accurate Chemical \& Scientific Corporation) and mouse anti-NeuN (1:500; Millipore Bioscience Research Reagents) in TBS + for overnight at $4^{\circ} \mathrm{C}$. The fluorescent secondary antibodies used were biotinylated donkey anti-rat IgG; Cy2-conjugated Streptavidin; donkey anti-mouse IgG conjugated with Cy3 (all 1:250; Jackson ImmunoResearch). Sections were then washed with TBS+, and then coverslipped in polyvinyl alcohol with diazabicyclo-octane (PVA-DABCO, Sigma) as anti-fading agent.

Quantification of BrdU-labeled cells and lateral ventricle volume. Brain sections were visualized and imaged using an Olympus Fluoview confocal laser scanning microscope. Images at each wavelength were collected separately, using a separate and specific excitation filter. Image collection settings were approximately equivalent for all specimens, and were taken and recorded using a Fluoview 2.1 program. For quantitative analysis, $\mathrm{Z}$ series of $40 \mu \mathrm{m}$ depth were collected from every sixth section, with $2 \mu \mathrm{m}$ intervals between images. For the counting of BrdU-labeled cells in the SVZ, three determined areas $(150 \mu \mathrm{m} \times 150 \mu \mathrm{m})$ in each section were randomly chosen and all BrdU-nuclei in the selected areas were counted. Adjacent sections were stained with DAPI $(2.5 \mu \mathrm{g} / \mathrm{ml})$ and all DAPI-nuclei in three determined areas per each section were counted.

The volume of the ventricle was determined according to Cavalieri's principle (West and Gundersen, 1990), by multiplying the sum of the cross sectional areas by the spacing $\mathrm{T}$ between sampled sections. In each sampled section we additionally measured the length of the lateral wall of the ventricle and the thickness of the SVZ at five locations along the longitudinal extent of the lateral wall.

For counting BrdU-labeled cells in the dentate gyrus, $Z$ series of $40 \mathrm{~mm}$ depth were collected from every sixth section, with $2 \mathrm{~mm}$ intervals between images. All $\mathrm{BrdU}^{+}$cells in subgranular layer and granule cell layer were visualized through a $40 \times$ objective and counted. Resulting numbers were multiplied by six to obtain the estimated total number of $\mathrm{BrdU}^{+}$cells per granule cell layer or subgranular layer.
Neural progenitor cultures and self-renewal assay. NPCs that give rise to neurospheres were cultured from dissected subependymal tissue, including minimal regions of ependyma and striatum, in serum-free medium supplemented with the mitogens, EGF and b-FGF as described earlier (Morshead et al., 1994; Chiasson et al., 1999). In brief, micro-dissected tissue was chopped, resuspended in $5 \mathrm{ml}$ of dissociation solution ( $1 \times$ HBSS containing $1 \mathrm{~mm}$ EDTA and $0.05 \%$ Trypsin), incubated at $37^{\circ} \mathrm{C}$ for $30 \mathrm{~min}$ and subsequently filtered through $100 \mu \mathrm{m}$ strainer. The single cell suspension was harvested by centrifugation $(225 \times g$ for $10 \mathrm{~min})$ and finally resuspended in serum-free culture medium [SFM; Neurobasal medium containing $100 \mathrm{U} / \mathrm{ml}$ penicillin/streptomycin, $2 \mathrm{~mm}$ L-glutamine, $10 \mu \mathrm{g} / \mathrm{ml}$ heparin, $20 \mathrm{ng} / \mathrm{ml}$ b-FGF, $100 \mathrm{ng} / \mathrm{ml} \mathrm{EGF}$ and 2\% B-27 supplement (Invitrogen)] (Gritti et al., 1999; Vanderluit et al., 2004). Approximately, $1 \times 10^{4}$ viable cells from dissected SVZ tissue per animal were obtained and subsequently plated at 5 cells/ $\mu$ l cell density in SFM as suggested earlier (Ferron et al., 2007). Cultures were maintained at $37^{\circ} \mathrm{C}$ in $5 \% \mathrm{CO}_{2} /$ balance air. Proliferating neurospheres that are $<100 \mu \mathrm{m}$ in diameter started to appear in $\sim 10-12$ days in vitro (DIV). The number of neurospheres were counted and considered as the clonogenic capacity of NPCs. The number of neurospheres obtained was divided by total number of viable cells seeded, and this ratio is represented as the percentage of multipotent neurospheres from each animal, as previously described (Molofsky et al., 2006). To obtain single cell suspensions, the neurospheres were dissociated by trituration using Neurocult chemical dissociation solution (StemCell Technologies) and cultured through multiple passages without any change in morphology and growth properties. To assess self-renewal capacity, single $100 \mu \mathrm{m}$ in diameter primary neurosphere or that was copGFP labeled by LV-PS1 infection was picked using pasture pipette, chemically dissociated, collected by centrifugation and resuspended in $200 \mu \mathrm{l}$ of SFM and seeded into a single well in 96 well culture plate. After $8 \mathrm{DIV}$, the number of progeny neurospheres $\geq 40 \mu \mathrm{m}$ in diameter, were counted under phase contrast microscope or under epifluoresence scope for detecting $\mathrm{GFP}^{+}$secondary spheres.

Immunofluorescence and immunoblotting of NPC cultures. For immunodetection of Nestin expression, 10-15 neurospheres were transferred using a Pasteur pipette onto a 4-well Lab-Tek II chamber slide precoated with poly-L-ornithine (Nalge Nunc) containing $1 \mathrm{ml}$ of serum-free medium. Four days later, the neurospheres adhering to the slide chamber were fixed with cold methanol for $5 \mathrm{~min}$ at $-20^{\circ} \mathrm{C}$, blocked for $30 \mathrm{~min}$ at room temperature with PBS containing $0.05 \%$ Triton X-100 (PBST) and $10 \%$ normal horse serum. Samples were washed with PBST and incubated with mouse monoclonal anti-Nestin antibody (clone R-401, 1:100; Dr. D. Geschwind, University of California at Los Angeles, Los Angeles, CA) overnight at $4^{\circ} \mathrm{C}$. Slides were rinsed three times with PBST, incubated for $1 \mathrm{~h}$ with fluorescein-conjugated donkey anti-mouse secondary antibody diluted in PBST (1:250, Jackson ImmunoResearch), washed, stained with DAPI (Calbiochem) and mounted. Fluorescence was visualized and images were captured using Olympus IX-81 inverted microscope. For immunoblotting analysis, neurosphere protein samples were prepared in lysis buffer $(150 \mathrm{~mm}$ $\mathrm{NaCl}, 50$ mm Tris pH 7.4, 5 mm EDTA, 0.5\% NP-40, 0.5\% sodium deoxycholate and protease inhibitor cocktail), fractionated by electrophoresis in Tris-Tricine polyacrylamide gels ( $25 \mu \mathrm{g} / \mathrm{lane})$, transferred to nitrocellulose membranes and immunoblotted with antibodies raised against the $\mathrm{N}$ terminus or loop domains of PS1 (Kim and Sisodia, 2005).

NPC proliferation assays. Proliferation rate of NPCs was measured by BrdU incorporation using a nonisotopic quantitative immunoassay kit (Calbiochem). A total of $100 \mu \mathrm{l}$ of a $2 \times 10^{5}$ cells $/ \mathrm{ml}$ single cell suspension of dissociated neurospheres were seeded in individual wells of 96 well culture plate containing $10 \mu \mathrm{M} \mathrm{BrdU}$, diluted in serum-free medium. After days 1, 2, 3 and 5, the extent of BrdU-uptake was determined by fixing the cells, denaturing the DNA and immunostaining for BrdU, with reagents supplied by the manufacturer and measured using a spectrometric plate reader at dual wavelengths of $450-595 \mathrm{~nm}$. To ensure validity of the experiment, for each time point, wells with only the culture medium (no cells) and cells without BrdU label were included in the assay. For immunocolabeling with nestin and BrdU, single cell suspension of primary neurospheres $\left(\sim 0.5 \times 10^{5}\right.$ individual cells $)$ were plated onto a 4-well Lab-Tek II poly-L-ornithine-precoated chamber slide in serum-free medium supplemented with $10 \mu \mathrm{M}$ BrdU on mentioned days 
and cultures were fixed ( $2 \% \mathrm{PFA}, 10 \mathrm{~min}$ at room temperature), treated with $1 \mathrm{~N} \mathrm{HCl}(5 \mathrm{~min})$ followed by $0.1 \mathrm{~m}$ borate buffer $(5 \mathrm{~min})$, blocked with PBST and 10\% normal donkey serum and processed for immunostaining with anti-nestin and BrdU antibodies as described earlier (Song et al., 2002; Choi et al., 2008).

Multipotency of NPCs. Primary neurospheres were dissociated into single cell suspension and $\sim 1 \times 10^{5}$ individual cells were plated onto a 4 -well Lab-Tek II poly-L-ornithine-precoated chamber slide containing $1 \mathrm{ml}$ of differentiation inducing medium (DIM; Neurobasal medium supplemented with $100 \mathrm{U} / \mathrm{ml}$ penicillin/streptomycin, $2 \mathrm{mM} \mathrm{L-glutamine,} 10 \mu \mathrm{g} / \mathrm{ml}$ heparin, 2\% B-27 and 3\% fetal bovine serum). After $10 \mathrm{~d}$, adherent cells were fixed and processed for immunofluoresence staining to detect lineage specific antigens: neuronal marker, $\beta$ III-tubulin (TUJ1, 1:200; Covance Research Products); astrocyte markers GFAP (1:500, Dako) and s100 $\beta$ (1:3000, Swant); oligodendrocyte marker, O4 (1:100; StemCell Technologies). Appropriate dilutions of secondary antibodies where used for single or double immunolabeling (fluorescein-conjugated donkey anti-mouse and Texas red-conjugated anti-rabbit; Vector Laboratories). Digital images were captured with inverted MTI-CCD camera attached Olympus IX81 fluorescence microscope and analyzed by StereoInvestigator software (MicroBrightField, Inc). The number of lineage committed cell type was quantified by examining a minimum of 300 cells (identified by DAPI-stained nuclei) at $20 \times$ objective magnification and represented as percentage differentiated cell type, as described previously (West, 1999; Ray and Gage, 2006). For GFP expressing viral transduced cultures, similar immunostaining procedure was followed except for fixing the cells with $4 \%$ PFA for 10 min followed by three washes with PBS and subsequent exposure to cold methanol for $10 \mathrm{~s}$. For quantification, a minimum of 50-100 $\mathrm{GFP}^{+}$cells from random fields were counted for each cell fate lineage.

Transduction of NPCs with lentivirus and retrovirus. Recombinant lentivirus encoding PS1hWT or FAD-linked PS1 variants and copepod GFP transgenes were generated using pCDH1-MCS1-EF1-copGFP selfinactivating lentivector in $293 \mathrm{TN}$ cells (System Biosciences) by following the three-plasmid packaging procedure as described previously (Naldini et al., 1996). In brief, cDNAs coding for PS1hWT, PS1 $\Delta \mathrm{E} 9$, PS1M146L, PS1C410Y, PS1A246E, PS1L286V and PS1D257A/D385A were subcloned into NheI and BamHI sites downstream to CMV promoter and sequence verified. Likewise, cDNA encoding HA-tagged truncated Notch1-ICD without OPA and PEST regions, but including RAM domain, ankyrin repeats and nuclear localization signal [from amino acid 1744 (5232 bp) up to the XhoI site at 6655 bp on mouse Notch 1 cDNA], was cloned into EcoR1 and BamH1 sites of pCDH1-MCS1-EF1-copGFP lentivector from mNotch. PCR products spanning these regions were amplified from pME-FNIC template that encodes FLAG-tagged membrane tethered full-length Notch1-ICD (5188-7672 bp; gift from Dr. Ryoichiro Kageyama, Institute for Virus Research, Kyoto, Japan].

pCDH1-Lentivector (9 $\mu \mathrm{g}$ /plate), pCMV $\Delta$ R8.9 expressing HIV gag/ pol, Rev and tat (12 $\mu \mathrm{g} /$ plate) (gift from Dr. Xiaobin Yu, Johns Hopkins University, Baltimore, MD), and pMD.G vector expressing VSV.G (3 $\mu \mathrm{g} /$ plate) were transfected into $10,150 \mathrm{~mm}$ culture dishes using Lipofectamine Plus reagent (Invitrogen) (Yu et al., 2003). Seventy-two hours after transfection, supernatant were collected and lentivirus were concentrated by sucrose cushion ultracentrifugation or by using PEG-it virus precipitation solution (System Biosciences) and the viral tires were determined in 293 cells, as described earlier (Capowski et al., 2007). Expression of human PS1 polypeptides and their ability to process APP-CTF substrate were confirmed by transducing $3 \times 10^{5} \mathrm{PS}$-deficient fibroblasts at an MOI of 30 for $24 \mathrm{~h}$ and $7 \mathrm{~d}$ later cells were lysed and total protein was subjected for immunoblotting analysis with PS1 NT, APP 369 or GFP (Axxora) antibodies. Expression of Notch1-ICD polypeptide from the LV-HANotch1-ICD was confirmed by transducing HEK 293 cells and immunoblotting the lysate with anti-HA antibody (Clone 12CA mouse monoclonal, Roche Bioscience). For self-renewal and differentiation assays, NPCs were transduced with mentioned lentivirus at an MOI of 30 for $24 \mathrm{~h}$, respectively, in SFM supplemented with $10 \mu \mathrm{g} / \mathrm{ml}$ polybrene. The lineage fate of 50-100 GFP ${ }^{+}$cells were scored for estimating the differentiation property of lentivirus-transduced NPCs.

Recombinant retrovirus encoding GFP or Hes1 transgenes were generated using pLXSN-GFP or pLXSN-mycHes1 retroviral vectors (Wu et al., 2003) packaged in VSV-G pseudo typed phoenix helper cells as described previously (Pear et al., 1993). Cell suspension of $1 \times 10^{5} \mathrm{NPCs}$ were transduced with pLXSN-GFP or pLXSN-mycHes 1 retrovirus at an MOI of 100 for $12 \mathrm{~h}$ and $12 \mathrm{~d}$ later processed either for immunoblotting with 9E10 sera or assessment of multipotency and self-renewal capacity as described above. All the viral experiments were performed in a BL2 containment tissue culture hood in accordance with BL3 practices approved by institutional biosafety committee.

Notch/CBF-responsive promoter/reporter lentivectors. Transcriptional regulatory region of mouse Hes 1 gene from -467 to $+46 \mathrm{bp}$ with (WtHes1-LV-Luc) or without (mut-Hes1-LV-Luc) CBF-1 interacting element (Takebayashi et al., 1994; Jarriault et al., 1995) was subcloned into SpeI and NheI sites upstream to minimal CMV promoter elements of the pTRH2-mCMV-Luc PathNet transcriptional reporter lentivector (Proless-Luc) (System Biosciences). Likewise, the four copies of wildtype (GATCTGGTGTAAACACGCCGTGGGAAA AAATTTATG) or mutant (GATCTGGTGTAAACACGGGCTTGGAAAAAATTTATG) CBF1 response elements were PCR amplified from GL2pro vector (Shawber et al., 1996) (gift from Dr. Nicholas Gaiano, Johns Hopkins Medical Institution, Baltimore, MD) and cloned into EcR1 and BamH1 sites of pTRH2-mCMV-Luc PathNet transcriptional reporter lentivector to generate Wt- $4 \times$ CBF1RE-LV-Luc and Mut- $4 \times$ CBF1RE-LV-Luc constructs, respectively. Lentivirus was packaged in 293TN cells, concentrated as described above and titers were estimated using QuickTiter Lentivirus quantification kit (Cell Biolabs). For reporter assays in PS ${ }^{+/+}$ and PS-deficient fibroblasts, $2 \times 10^{5}$ cells we transduced with ProlessLuc, Wt-LV-Luc or mut LV-Luc lentivirus at an MOI of 30 for $12 \mathrm{~h}$. Forty-eight hours later, the cells were transiently transfected with cAPICN encoding transmembrane region, RAM domain, cdc 10/ankyrin repeats and nuclear localization signal of Notch 1 receptor; or mock vector, cAP. For normalization purpose, each group of cells was cotransfected with 50 ng of pCMV-Renilla luciferase expression plasmid. Seventy-two hours later, cells were lysed and firefly luciferase activity was measured in a Turner Designs 20/20 Luminometer, using Dualluciferase reporter assay system (Promega). For reporter assays in NPCs, $1 \times 10^{5}$ single cell suspension of progenitors was infected with reporter lentivirus at an MOI of 10 for $12 \mathrm{~h}$ in SFM. Seven days later, the cultures were reinfected with lentivius carrying PS1hWT or mutant PS1 transgenes at an MOI of 30 for $12 \mathrm{~h}$. The cultures were then lysed after $7 \mathrm{~d}$ and luciferase activity was measured as described above and normalized in reference to total protein content.

RT PCR analysis. Total RNA from primary cultures of NPCs established from 2 months old PS1hWT or PS1 $\Delta \mathrm{E} 9$ transgenic mice was isolated in Trizol Reagent and $1 \mu \mathrm{g}$ of RNA was reverse transcribed using the Superscript III synthesis kit (Invitrogen). PCR was performed using the following primers: Notch 1 sense 5' -CCAGCATGGCCAGCTCTGG- 3'; Notch 1 antisense $5^{\prime}$-CATCCAGATCTGTGGCCCTGTT-3'; Jagged 1 sense 5'-GTCCACGGCACCTGCAATG-3'; Jagged 1 antisense 5'-CAAGGTTTGGCCTCGCACT-3'; Deltal sense 5'-ACTCCTTCAGCCTGCCTGA-3'; Deltal antisense 5'-TATCGGATGCACTCATCGC-3'; CBF1 sense 5'-TGGCACTGTTCAATCGCCTT-3'; CBF1 antisense 5'-AATCTTGGGAGTGCCATGCCA-3'; Hes1 sense 5'-AAAGACGGCCTCTGAGCACA-3'; Hes1 antisense 5'-TCATGGCGTTGATCTGGGTCA-3'; GAPDH sense 5'-ACCACAGTCCATGCCATCAC-3'; GAPDH antisense 5' -TCCACCACCCTGTTGCTGT-3'.

Quantitative PCR was performed using certified RT ${ }^{2}$ qPCR primers (SuperArray Bioscience Corp) for mouse GAPDH, Hes1 (Ref.Seq \# NM_008235.2), Hes5 (Ref.Seq \# NM_010419.2), Hes7 (Ref.Seq \# NM_033041.2), Hey1 (Ref.Seq \# NM_010423.2) and Hey2 (Ref.Seq \# NM_013904.1) in RT $^{2}$ real-time SYBR green/Fluorescein PCR mix with $1 \mu \mathrm{l}$ of 1:10 diluted first strand cDNA template. Actin Forward 5'-GGACCTGACGGACTACCT CATG-3', Reverse 5' -TCTTTGATG TCACGCACGATTT- $3^{\prime}$. $C_{\mathrm{t}}$ values were determined by performing the real-time PCRs on a Bio-Rad I-Cycler iQ using the following program: $95^{\circ} \mathrm{C}, 15 \mathrm{~min} ; 40$ cycles of $95^{\circ} \mathrm{C}, 30 \mathrm{~s} ; 55^{\circ} \mathrm{C}, 30 \mathrm{~s}$; and $72^{\circ} \mathrm{C}$, $30 \mathrm{~s}$; and fold changes where calculated by $\Delta \Delta C_{\mathrm{t}}$ method.

Statistical analysis. Data are expressed as mean values \pm SEM $(\mathrm{m} \pm \mathrm{SEM})$. Student's $t$ test or ANOVA was performed for all comparisons of quantita- 
tive data. Values of $p<0.05$ were used as the criterion for statistical significance.

\section{Results}

FAD-linked PS1 mutants impair the self-renewal potential of cultured adult SVZ NPCs

To determine whether expression of FADlinked PS1 variants affect self-renewal capacity of progenitor cells, we established neural progenitor derived neurosphere cultures from dissected SVZ of 4- to 8-weekold adult male mice (Fig. 1Ai). Cells within the neurosphere cluster expressed the subependymal neural progenitor marker antigens, nestin (Fig. 1 Aii) and glial fibrillary acidic protein (GFAP) (Fig. 1 Biv) (Garcia et al., 2004) and the multipotency of these cells were confirmed by detecting distinct neuronal, $\beta$ III-tubulin ${ }^{+}$, or glial, GFAP ${ }^{+}$cells upon differentiation (Fig. 1Avi-viii).

We generated recombinant lentiviral vectors (LVs) containing dual promoters that drive expression of either human wild-type PS1 (PS1hWT) or FAD-linked PS1 mutant transgenes together with the copepod green fluorescent protein (GFP) (Fig. $1 B$ ). To confirm that the LVs express the gene products of interest, we transduced PS-deficient immortalized mouse fibroblasts with each of the LVs and performed Western blot analysis of detergent lysates using a PS1 NT antibody (Kim and Sisodia, 2005) (Fig. 1C). These studies revealed that comparable levels of PS1hWT and mutant PS1 proteins were expressed in LV-transduced cells. As expected, the presence of both full-length PS1 ( 42-50 $\mathrm{kDa}$, holoprotein) and the endoproteolytically processed $\mathrm{N}$-terminal derivatives ( 27-30 kDa) were observed in cells transduced with LV encoding PS1hWT, PS1M146L, PS1L286V or PS1A246E, while only the unprocessed full-length mutant PS1 was detected in cell lysates prepared from cells transduced with LV encoding human PS1 $\Delta \mathrm{E} 9$ or PS1C410Y, as previously reported (Thinakaran et al., 1996). Analysis of accumulated endogenous APP C-terminal fragments (APP-CTF) in PSdeficient fibroblasts (Xia et al., 1998; Chen et al., 2000), confirmed that LV-transduced cells expressing PS1hWT or PS1 variants have differential effects on $\gamma$-secretase activity (see supplemental Fig. 1, available at www.jneurosci.org as supplemental material) (Bentahir et al., 2006).

Having established that the LVs expressed the appropriate PS1 polypeptides, we then transduced single cell suspensions of SVZ NPCs with these vectors and assayed the self-renewal capacity in serum-free conditions, in vitro. Self-renewing NPCs, transduced with LV generated secondary neurospheres and were identified by GFP expression (Fig. $1 D$, top). The number of progeny neurospheres that were $\geq 40 \mu \mathrm{m}$ in diameter, generated from a single $\mathrm{GFP}^{+}$primary neurosphere (100 $\mu \mathrm{m}$ in diameter), were quanLV-PS1 mutants.
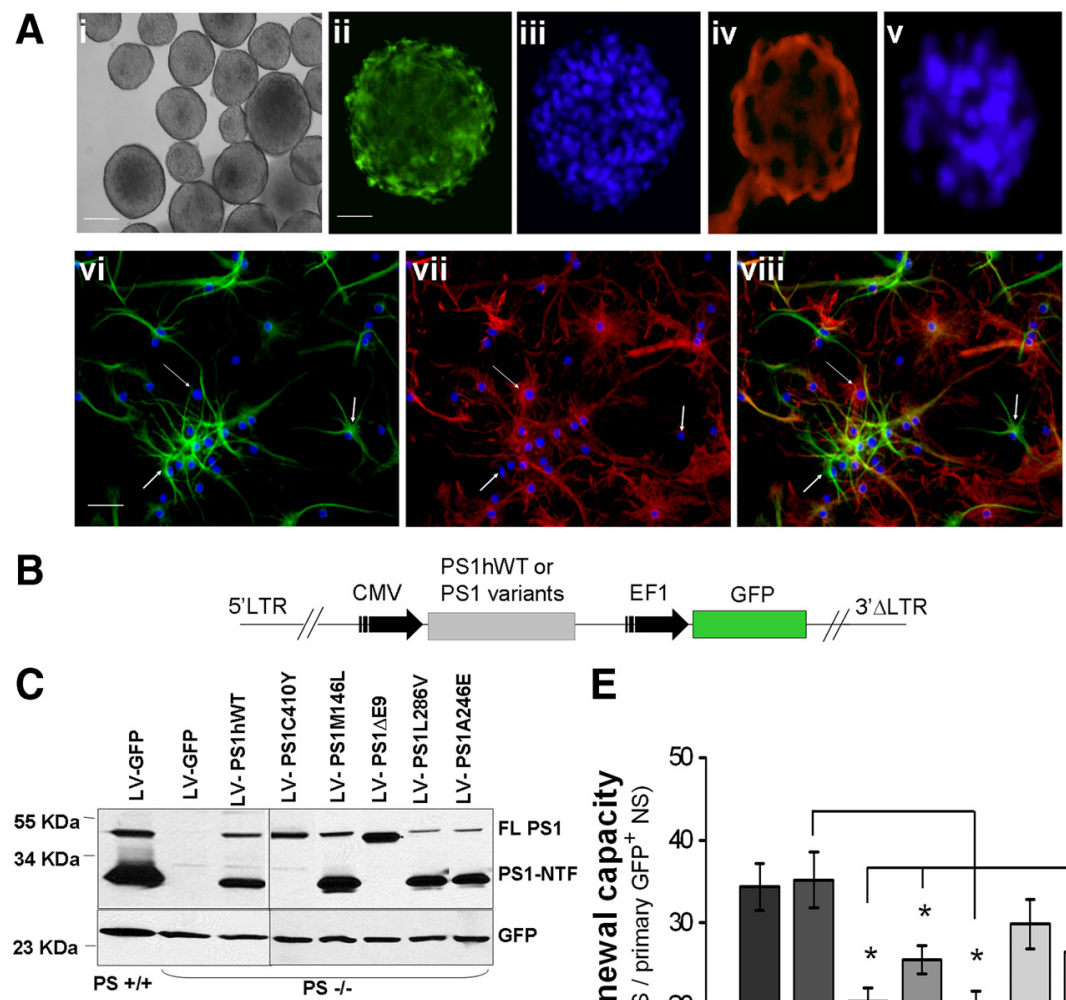

E

Figure 1. Self-renewal capacity of NPCs expressing FAD-linked PS1 mutants. $\boldsymbol{A}, \mathrm{NPC}$ grown as neurospheres from dissected SVZ of adult mice in serum-free medium conditions (i). Scale bar, $50 \mu \mathrm{m}$. Immunoreactivity of neurosphere for NPC marker antigens, nestin (ii; green) and GFAP (iv; red). Nuclei were stained with DAPI (iii, $\boldsymbol{v}$; blue). Scale bar, $25 \mu \mathrm{m}$. Lineage committed progeny cells with distinc immunoreactivity to $\beta \mathrm{Ill}$-tubulin (vi; green, thick arrow) or GFAP (vii; red, thin arrow) were observed following differentiation of NPCs and the overlay of (vi) and (vii) is shown in viii. Scale bar, $10 \mu \mathrm{m}$. $\boldsymbol{B}$, Illustration of lentiviral vector constructs encoding CDNAs for PShWT or PS1 with mentioned lentivirus were Tris-Tricine SDS-PAGE resolved and immunoblotted with either human PS1 N-terminal fragment (NTF) or antisera. Protein $(25 \mu \mathrm{g})$ was loaded in each lane. D, LV-transduced NPCs that self-renewed as neurospheres under serum-free conditions expressed GFP ( $-F B S$ ). Left and the middle panel on the top row show the bright-field and fluorescent images of LV-transduced eurospheres under $10 \times$ objective, respectively (Scale bar: $50 \mu \mathrm{m}$ ). Magnified image of a copGFP ${ }^{+}$neurosphere captured under $20 \times$ 列 he expression of GFP (+FBS, bottom row; bright-field and the respective fluorescent image of transduced progenitor cells; scale bar, 10 ). Tracing of infected cells by GFP expression was used to evaluate the effect of PS1 mutants on self-renewal and differentiation of adult SVZ NPCs. $\boldsymbol{E}$, Self-renewal capacity of GFP ${ }^{+}$NPCs (neurosphere, NS) transduced with lentivirus encoding PShWT or various FAD-PS1 mutant CDNA. Data represent $\mathrm{m} \pm$ SEM obtained from 6 independent experiments. ${ }^{*} p<0.05$ for NPCs transduced with LV-PS1hWT vs

tified. Compared with NPCs transduced with LV-PS1hWT, expression of PS1 $\Delta$ E9, PS1M146L, PS1C410Y or PS1A246E significantly impaired the ability of NPCs to generate progeny neurospheres (Fig. $1 E ; p<0.05$ for PS1hWT vs PS1 variants). While the level of impairment was variable across the mutants, the PS1 1 E9 and PS1C410Y showed the strongest inhibition of selfrenewal capacity.

Effects of FAD-linked PS1 mutants on multilineage potential of cultured adult SVZ NPCs

The self-renewal property of adult NPC is governed by the delicate balance between proliferation, maintenance of undifferenti- 

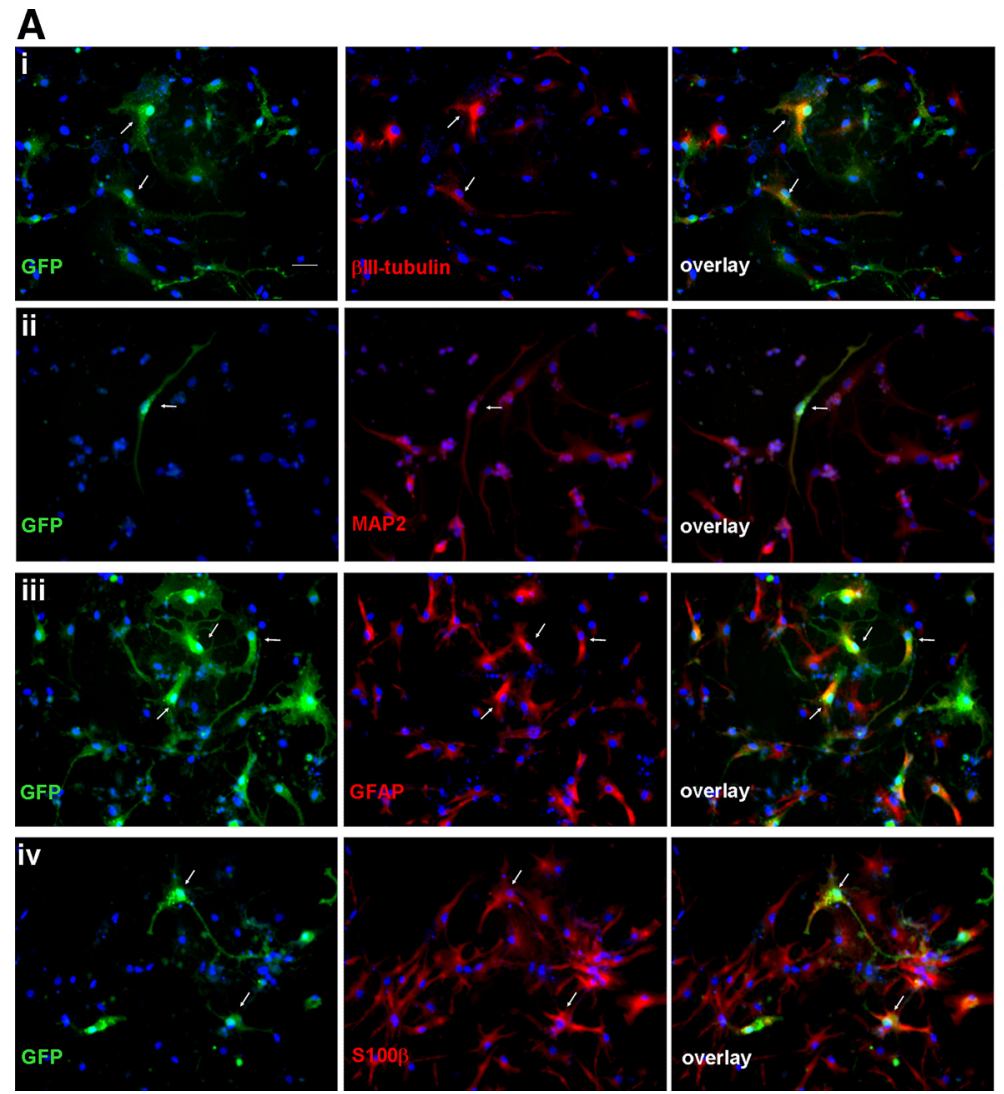
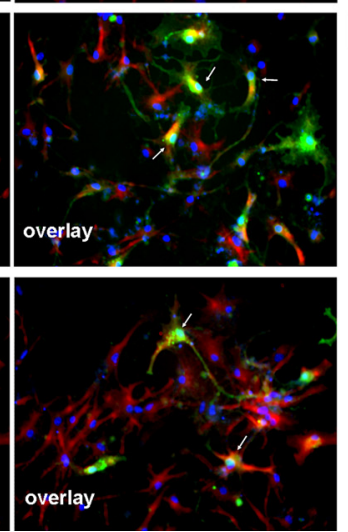
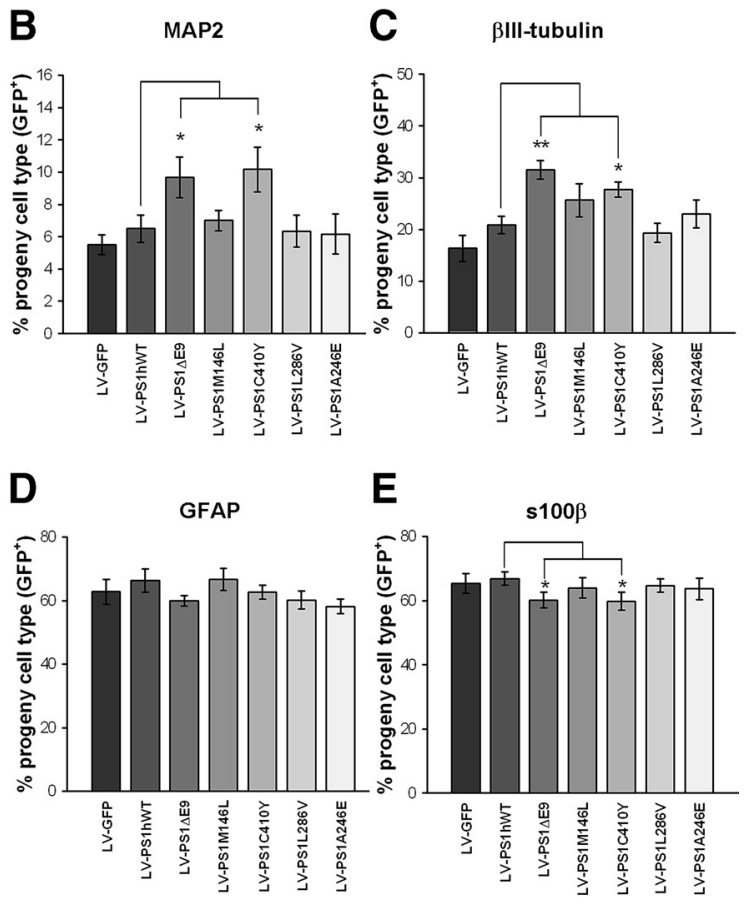

Figure 2. Multilineage potential of NPCs expressing FAD-linked PS1 mutants. $A$, Representative photomicrographs reveal the identity of LV-PS1-transduced, GFP + NPCs (arrow), differentiated into $\beta$ III-tubulin (row i), MAP2 (row ii), GFAP (row iii) or s100 $\beta$ (row iv) lineages. Overlay of the respective images are shown on the right of each row. Scale bar, $25 \mu \mathrm{m}$. $\boldsymbol{B}-\boldsymbol{E}$, Quantification of GFP + progenitors differentiated to neuronal or astroglial progeny cell types. Data represent $m \pm$ SEM obtained from 3 independent experiments and the differentiated fate was scored by counting a minimum of $100 \mathrm{GFP}^{+}$cells that colabeled with neuronal or astrocyte cell fate marker. ${ }^{*} p<0.05 ;{ }^{* *} p<0.01$, for NPCs transduced with LV-PS1hWT vs LV-PS1 variants.

ated state and exit toward lineage commitment (for review, see Molofsky et al., 2004). Encouraged by our findings on the effect of the FAD-linked PS1 mutants on self-renewal (Fig. $1 E$ ), we next examined the effects of PS1hWT or PS1 mutants on seruminduced differentiation of SVZ NPCs, and in this case, used GFP to track the fate of the transduced progenitor cells (Fig. $1 D$, bottom). In differentiation assays (representative images are shown in Fig. 2A), quantitative analysis of cells colabeled with GFP and the neuronal antigens, MAP2 or $\beta$ III-tubulin, revealed that compared with PS1hWT, expression of PS1DE9 or PS1C410Y mutants resulted in enhanced commitment of NPCs toward the neuronal lineage (Fig. $2 B, C$ ). On the other hand, expression of FAD-linked PS1 variants failed to significantly alter the percentage of NPCs that exhibit GFAP ${ }^{+}$astrocytic fate (Fig. $1 D$ ). However, the percentage of NPCs differentiating into $s 100 \beta^{+}$glial fate was significantly decreased in cultures that expressed PS1 $\Delta$ E9 or PS1C410Y (Fig. 1E). Collectively, these in vitro studies indicated that of all the PS1 mutants tested, expression of the PS1 $\Delta$ E9 and PS1C410Y significantly impaired the self-renewal capacity of adult SVZ-derived NPCs and promoted differentiation toward a neuronal lineage.

Steady-state level of progenitor pool is reduced in postnatal SVZ of transgenic mice model expressing PS1 1 E9 variant A strong link has been established between the self-renewal potential measured in vitro, and the proliferation rate of NPCs observed in vivo in the SVZ of adult mice (Molofsky et al., 2006). Therefore, we quantified NPC proliferation in the SVZ of 2-month-old adult transgenic mice harboring mouse prion promoter (PrP)-driven transgenes that encode either PS1hWT or PS1 $\mathrm{E} 9$ (Borchelt et al., 1996). For these studies, mice were injected intraperitoneally with a single dose of $50 \mathrm{mg} / \mathrm{kg} \mathrm{BrdU}$, killed $2 \mathrm{~h}$ after injection and brain sections were subject to immunocytochemical analysis using antibodies specific for BrdU (Fig. 3A). Design-based stereological system was used to quantify the number of $\mathrm{BrdU}^{+}$cells in randomly determined areas of 40 $\mu \mathrm{m}$ thick sections spanning the three sampling zones of the anterior ventricle along the rostrocaudal axis (supplemental Fig. $2 A$, available at www.jneurosci.org as supplemental material). Cumulative data revealed that number of constitutively proliferating $\mathrm{BrdU}^{+}$cells in the SVZ of mice expressing PS1 $\Delta \mathrm{E} 9$ variant (Fig. $3 B$ ) was significantly reduced by $\sim 20 \%$ compared with number of BrdU ${ }^{+}$cells in PS1hWT littermates (PS1hWT $30.71 \pm 1.12$ vs PS1 $\Delta$ E9 $25.38 \pm 1.71$ per $\left.150 \mu \mathrm{m}^{2} ; p=0.0315\right)$. As a control, we examined the number of BrdU-labeled cells in the subgranular layer of the dentate gyrus of standard housed adult PS1hWT and PS1 $\triangle \mathrm{E} 9$ animals that also received a single dose of $50 \mathrm{mg} / \mathrm{kg}$ BrdU and were killed $2 \mathrm{~h}$ after injection. As we reported earlier (Choi et al., 2008), using a single bolus, $24 \mathrm{~h}$ labeling paradigm (supplemental Fig. $2 F$, available at www. jneurosci.org as supplemental material), we observed no significant differences in the numbers of subgranular layer NPCs in adult PS1hWT and PS1 $\Delta$ E9 animals (Fig. 3B; PS1hWT $1572.00 \pm$ 86.12 , PS1 $\Delta$ E9 $1680.00 \pm 71.70 ; p=0.3634)$. To confirm that the differences in proliferating $\mathrm{BrdU}^{+}$cells in the SVZ of mice expressing PS1hWT and PS1 $\Delta$ E9 variant was not the effect of gross 
anatomical change in the size of SVZ between the two strains of mice, we performed DAPI staining (supplemental Fig. $2 B$, available at www.jneurosci.org as supplemental material). We did not observe any significant differences in the volume of lateral ventricles, length of the lateral wall or the thickness of subventricular layer between the two genotypes (supplemental Fig. 2C-E, available at www.jneurosci.org as supplemental material). Furthermore, the number of DAPI-stained cells in sections adjacent to the designated areas within the SVZ of PS1 $1 \mathrm{E} 9$ mice was not different from that of PS1hWT mice (PS1hWT, $129.51 \pm$ 0.98 vs $\mathrm{PS} 1 \Delta \mathrm{E} 9,131 \pm 0.73)$. Thus, expression of human PS1 $\Delta \mathrm{E} 9$ variant does not affect gross measures of SVZ architecture at 2 months age, leading us to argue that constitutive progenitor proliferation observed within the germinal zone of adult SVZ is indeed attenuated by expression of the PS1 $\Delta \mathrm{E} 9$ variant.

To assess whether the reduced number of BrdU-labeled cells in PS1 $\Delta \mathrm{E} 9$ mice might be a reflection of decreases in the neural progenitor pool, we used a clonogenic in vitro neurosphere assay (Ferron et al., 2007). Equal numbers of cells from dissected subependymal tissue of 2- to 3-month-old adult PS1hWT and PS1 $\Delta$ E9 mice were plated at the same density, and the frequency of mutipotent neurosphereforming cells were determined. Expression of PrP-driven human PS1 polypeptides was confirmed by Western blot analysis of detergent lysates prepared from these cultured adult SVZ-NPCs with PS1 NT and PS1-loop antibodies (Fig. 3C). Quantifying the number of clonally generated primary neurospheres ( $\geq 40 \mu \mathrm{m}$ in diameter) after 12 days in vitro revealed that of the total number of cells plated, $\sim 2.42 \%$ of cells had the ability to proliferate and grow as neurospheres in cultures established from the subependymal tissue of PS1hWT mice. Remarkably, only $\sim 1.34 \%$ of cells grew as neurospheres in cultures established from PS1 $1 \mathrm{E} 9$ mice, a significant decrease in the frequency than that observed in cultures plated from PS1hWT mice (PS1hWT, $2.4236 \pm$ 0.0919 vs PS1 $\Delta \mathrm{E} 9,1.3403 \pm 0.0927 ; p<0.01$, data obtained from independent cultures established from 9 animals per group), findings that are fully consistent with the $2 \mathrm{~h}$ in vivo BrdU labeling studies (Fig. 3B).

Assessment of the competence of these primary neurospheres to generate secondary neurospheres revealed that the selfrenewal potential of PS1 $\triangle$ E9 SVZ NPCs were significantly lower than PS1hWT NPCs (PS1hWT, 32.2 \pm 3.6249 vs PS1 $\Delta$ E9, $20.6 \pm$ $1.8055 ; p=0.0209, N=5)$. To investigate whether the observed difference in self-renewal capacity could be attributed to changes in proliferation rate of NPCs, PS1hWT and PS1 $\triangle$ E9 NPCs were plated at equal number and density in serum-free medium containing BrdU. BrdU incorporation on day 1 through 5 was determined using an ELISA-based assay (Fig. 3D). On day 1, the extent of BrdU incorporation was similar across all NPC cultures, implying that the initial cell numbers at plating were equivalent.
B

C
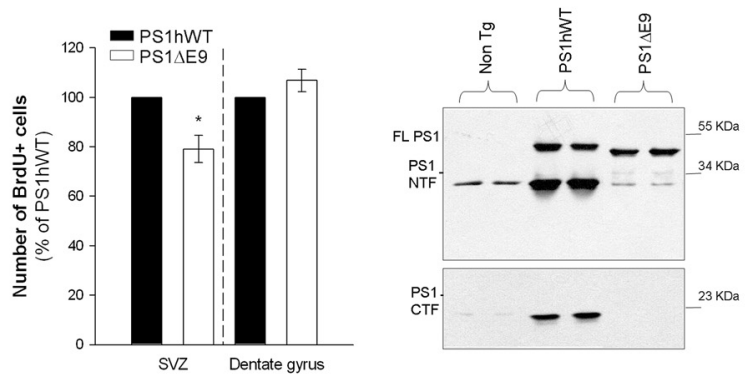

E

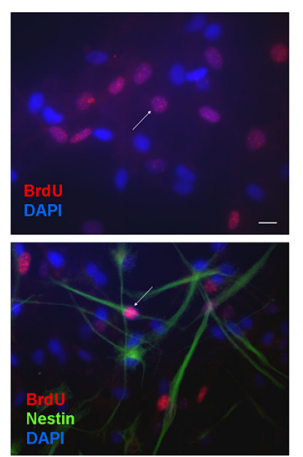

$\mathbf{F}$

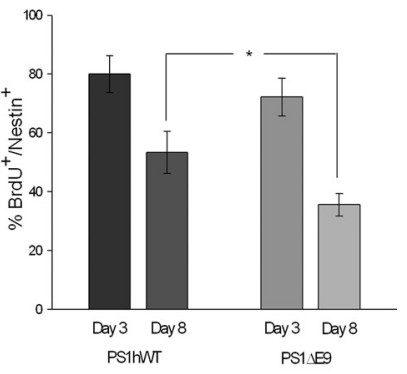

Figure 3. Steady-state levels of progenitor pool in postnatal SVZ of PS1 $\Delta$ E9 transgenic mice. $\boldsymbol{A}$, Confocal images of BrdUbeled cells (green) in the SVZ of the lateral ventricle from adult transgenic mice expressing PS1hWT or PS1 $\triangle$ E9 variant. NeuN Prom adult transgenic mice expressing PS1hWT or PS1 $\Delta$ E9 were lysed; total protein was Tris-Tricine SDS-PAG $\mathrm{BrdU}^{+}$and nestin ${ }^{+}$cells scored on days 3 and 8 in independent NPC cultures expressing PS1hWT or PS1 $\triangle$ E9. Data were collected by sampling 30 nestin $^{+}$cells from two random fields for BrdU colabeling. $N=3,{ }^{*} p<0.05$.

Interestingly, by day 5, in comparison with PS1hWT, proliferation of NPC expressing PS1 $\Delta$ E9 was significantly retarded. Given the ELISA-based assay provides a cumulative score for total BrdUuptake in culture, we set out to specifically determine the number of proliferating nestin ${ }^{+}$neural progenitors that were $\mathrm{BrdU}^{+}$. To do so, independent cultures of PS1hWT or PS1 $\Delta$ E9 SVZ NPCs were exposed to serum-free medium containing $10 \mu \mathrm{M}$ BrdU on day 2 or 6 for $12 \mathrm{~h}$, and subsequently fixed on day 3 or 8 , respectively. Nestin ${ }^{+}$ NPCs that retained BrdU were identified by immunocolabeling (Fig. $3 E)$. By day 3 , an average of $\sim 80 \%$ and $72.2 \%$ of nestin ${ }^{+}$PS1hWT and PS1 1 E9 NPCs, respectively, retained BrdU (Fig. $3 F$ ). However, when labeled at day 6 and analyzed at day $8,53.3 \%$ of PS1hWT NPCs were nestin ${ }^{+} / \mathrm{BrdU}^{+}$, while only $35.5 \%$ PS1 $\Delta \mathrm{E} 9$ progenitors were nestin ${ }^{+} / \mathrm{BrdU}^{+}$(Fig. $3 F$ ). Collectively, the data obtained from in vivo BrdU labeling analysis, clonal neurosphere assays and in vitro nestin/BrdU colabeling analysis indicate that expression of the PS1 $1 \mathrm{E} 9$ variant leads to a reduction in the steady-state levels of SVZ progenitor pools in vivo and the self-renewal capacity and proliferation of NPCs in vitro.

\section{Adult SVZ NPCs from transgenic mice expressing the FAD-linked PS1 $\triangle E$ 9 variant exhibit altered cell fate commitment}

To investigate whether expression of the PS1 $\Delta \mathrm{E} 9$ variant affects the inherent differentiation potential of cultured neural progen- 
A
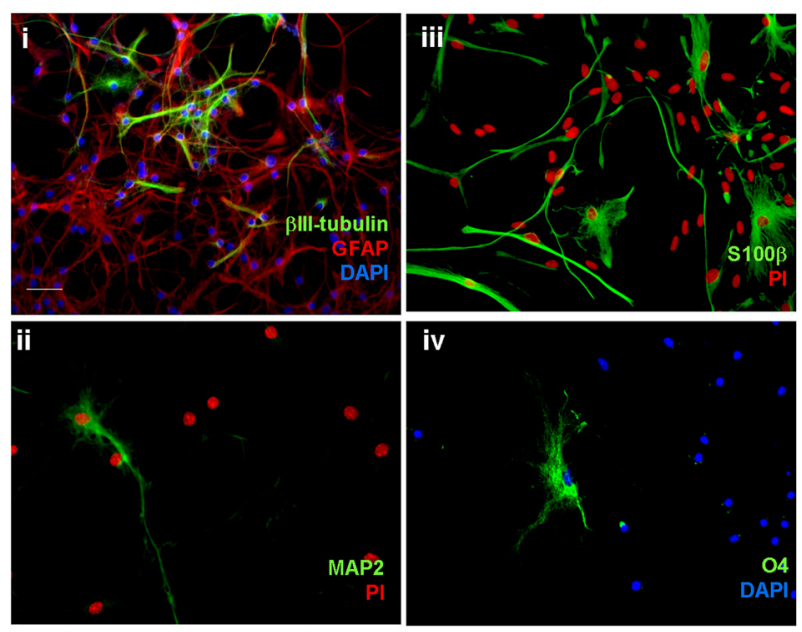

iv

B

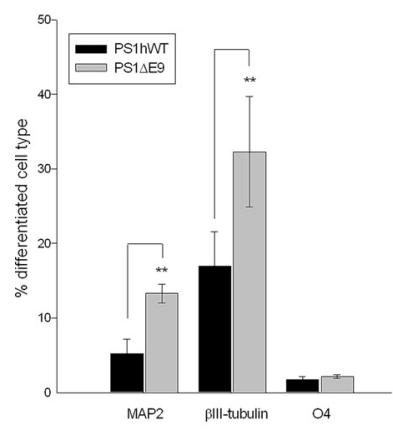

C

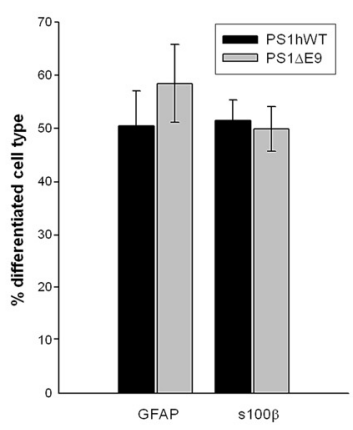

D

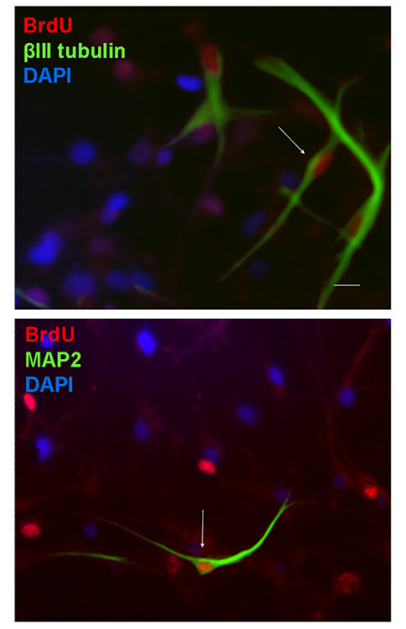

E

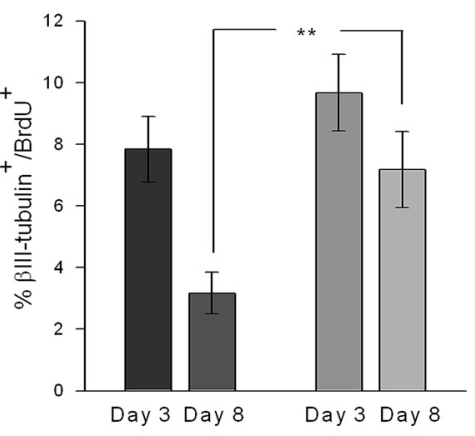

$\mathbf{F}$

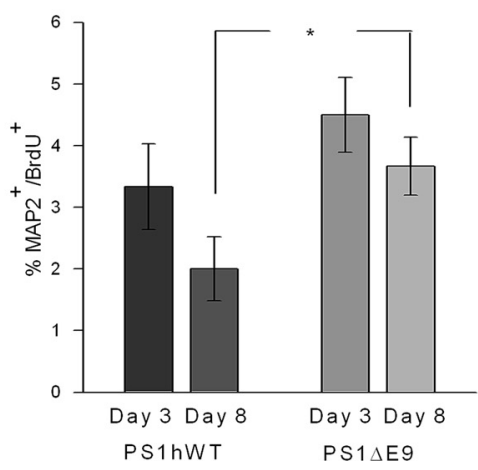

G

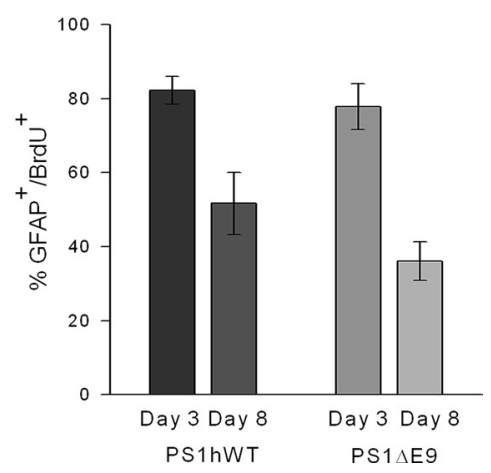

Figure 4. Multilineage commitment of NPCs derived from postnatal SVZ of PS1 $\Delta E 9$ transgenic mice. $A$, Representative photomicrographs reveal the differentiation potential of NPC cultures into distinct $\beta$ III-tubulin (i; green)-, GFAP (i; red)-, MAP2 (ii; green)-, s100 $\beta$ (iii; green)-, and 04 (iv; green)-positive cell types, established from SVZ of adult PS1hWT or PS1 $\Delta$ E9 transgenic mice. Scale bar, $25 \mu \mathrm{m}$. Nuclei were stained with DAPI (blue; $\boldsymbol{i}, \boldsymbol{i}$ ) or propidium iodide (PI, red; $\boldsymbol{i i}$, and iii). $\boldsymbol{B}, \mathbf{C}$, Quantification of differentiated progeny cell types. Number of animals per group $=5$, data were obtained by scoring a minimum of 300 cells for each lineage marker, ${ }^{* *} p<0.01$. D, Representative images of NPC-differentiated $\beta$ III-tubulin [green (arrow), top] or MAP2 [green (arrow), bottom] lineage and colabeled with BrdU (red). Nuclei were stained with DAPI. Scale bar, $10 \mu \mathrm{m}$. $\boldsymbol{E}$-G, Quantification of NPCs differentiated to $\beta$ III-tubulin (E), MAP2 (F), or GFAP (G) lineage and colabeled with BrdU, scored on days 3 and 8 in independent NPC cultures expressing PS1hWT or PS1 $\mathrm{E}$. Data were collected by sampling 100 BrdU ${ }^{+}$cells from random fields for colabeling with lineage-specific differentiation. $N=3,{ }^{*} p<0.05 ;{ }^{* *} p<0.01$.

itors, we subjected single cell suspensions of adult mouse-derived PS1hWT or PS1 1 E9 SVZ NPCs to a multipotency assay that is promoted by exposure to $1 \%$ fetal bovine serum. The number of differentiated neuronal, glial and oligodendrocyte progeny cell types after $10 \mathrm{~d}$ were estimated by immunostaining the cultures with antibodies specific for the neuronal markers $\beta$ III-tubulin and MAP2, the oligodendrocyte lineage marker O4, or the astrocytic markers GFAP or s100 $\beta$ (representative images are shown in Fig. 4A). Quantitative analysis revealed 16.9\%, 5.2\%, 50.4\%, $51.4 \%$ and $1.7 \%$ of the sampled cells that were derived from differentiating NPCs of PS1hWT mice were immunopositive for $\beta$ III-tubulin, MAP2, GFAP, S100 $\beta$ and O4, respectively (Fig. $4 B, C)$. Notably, in comparison with PS1hWT NPCs, a 1.9-fold increase in $\beta$ III-tubulin ${ }^{+}$and 2.5 -fold increase MAP2 ${ }^{+}$progeny cell types were observed in differentiated NPCs established from PS1 $\Delta$ E9 mice (Fig. $4 B$ ), a result that is consistent with the differentiation assays performed after LV delivery of the PS1 $\triangle E 9$ transgene into NPCs (Fig. 2B,C). No significant changes in the numbers of $\mathrm{GFAP}^{+}$or $\mathrm{S} 100 \beta^{+}$cell types were observed in differentiated PS1 $\triangle$ E9 NPCs (Fig. 4C).

To obtain an estimate of the fraction of dividing progenitors that differentiate into distinct lineages, we provided a pulse of BrdU at various time points of the multipotency assay and scored the phenotype of labeled cells. PS1hWT or PS1 1 E9 SVZ NPCs were subjected to the serum-induced differentiation paradigm and independent cultures were exposed to BrdU on day 2 or 6 for $12 \mathrm{~h}$, and subsequently fixed at the end of days 3 or 8 , respectively. Cells that retained BrdU and were differentiated to distinct neuronal or glial lineage were identified by immunocolabeling (Fig. $4 I$ ). We observed that on days 3 and $8,7.8 \%$ and $3.1 \%$, respectively, of differentiated PS1hWT NPCs were $\mathrm{BrdU}^{+} / \beta \mathrm{III}$ tubulin $^{+}$(Fig. 4E). On the other hand, the percentage of differentiated PS1 $\Delta$ E9 NPC cultures that were $\mathrm{BrdU}^{+} / \beta \mathrm{III}-$ tubulin ${ }^{+}$was reduced from $9.6 \%$ to only $\sim 7.1 \%$ between days 3 and 8 , respectively. The percentage of $\mathrm{MAP}^{+} / \mathrm{BrdU}^{+}$in differentiated PS1hWT cultures was $3.3 \%$ and $2 \%$ on days 3 and 8 , respectively (Fig. $4 F$ ). In contrast, the percentage of $\mathrm{MAP}^{+}{ }^{+}$/ $\mathrm{BrdU}^{+}$cells derived from differentiated PS1 $\triangle \mathrm{E} 9$ NPC cultures was reduced from $4.5 \%$ to only $\sim 3.6 \%$, at days 3 and 8 , respectively. In summary, we observed a significant elevation in the numbers and percentage of cells that were $\beta$ III-tubulin ${ }^{+} / \mathrm{BrdU}^{+}$- or $\mathrm{MAP}_{2}{ }^{+} / \mathrm{BrdU}^{+}$-labeled cells in differentiated PS1 $\Delta \mathrm{E} 9 \mathrm{NPC}$ cultures compared with PS1hWT NPC cultures at the $8 \mathrm{~d}$ time point. These results suggests that premature (or preferential) differentiation of newborn progenitors toward the neuronal lineage occurs more rapidly in PS1 $\triangle$ E9 NPC cultures, findings that support 
the observed decrease in in vitro proliferation (Fig. $3 D, F$ ) and increase in neuronal differentiation in and multipotency assays (Fig. $4 B$ ).

Parallel analysis of PS1hWT NPCs that differentiated into $\mathrm{GFAP}^{+} / \mathrm{BrdU}^{+}$cells revealed that $82.2 \%$ and $51.6 \%$ of cells were colabeled at days 3 and 8 , respectively (Fig. 4G). Similarly, $77.7 \%$ and $36.1 \%$ of differentiated PS1 $\mathrm{E} 9$ NPCs were $\mathrm{GFAP}^{+} / \mathrm{BrdU}^{+}$at days 3 and 8 , respectively. While there appears to be moderate decrease in the percentage of $\mathrm{BrdU}^{+}$cells that were $\mathrm{GFAP}^{+}$in PS1 $\Delta \mathrm{E} 9$ compared with PS1hWT cultures by day 8 , the observed reduction was not significant.

\section{Diminished Notch signaling in SVZ NPCs expressing FAD-linked PS1 variants}

Earlier reports have indicated that expression of the FAD-linked PS1 $\Delta \mathrm{E} 9$ and PS1C410Y variants impairs $\gamma$-secretasemediated intramembranous processing of Notch 1 and nuclear translocation of the Notch Intracellular Domain (NICD) in cultured mammalian cells (Song et al., 1999; Nakajima et al., 2000). Moreover, genetic ablation strategies have revealed a role for Notch signaling in regulating self-renewal of NPCs in the postnatal SVZ (Nyfeler et al., 2005). In view of these latter findings and our demonstration that proliferation of NPCs in the SVZ of adult PS1 $\Delta \mathrm{E} 9$ mice is impaired, we were prompted to investigate the impact of expressing the FAD-linked PS1 variants on Notch signaling in SVZ progenitors. We first examined the expression of genes involved in the canonical Notch pathway in SVZ-derived NPCs isolated from adult PS1hWT and PS1 $\Delta \mathrm{E} 9$ mice by RT-PCR. We demonstrated that transcripts encoding Notch1, the Notch ligands, Jagged1 and Delta1, the Notch effector, C-promoter binding factor (CBF-1), and the Notch target gene, Hes1, are present in SVZ-derived NPCs from these transgenic lines (see supplemental Fig. $3 A$, available at www. jneurosci.org as supplemental material).

We then determined the levels of Notch receptor activity in NPCs using a well established Notch/CBF-1-dependent promoter reporter assay that requires PS-dependent $\gamma$-secretase activity to mediate intramembranous processing of Notch, nuclear translocation of NICD and expression of the transcription factor, Hes1 (Schroeter et al., 1998; Martys-Zage et al., 2000). For these studies, we generated recombinant LV encoding a firefly luciferase reporter gene driven either by a minimal CMV promoter sequence (Proless-Luc), by the upstream regulatory region of the mouse Hes1 gene containing two CBF-1 binding elements (WtHes1-LV-Luc), or $4 \times \mathrm{CBF}-1$ response element (Wt- $4 \times \mathrm{CBF} 1 \mathrm{RE}-$ LV-Luc) (see supplemental Fig. $4 A$, available at www.jneurosci. org as supplemental material) (Takebayashi et al., 1994; Jarriault et al., 1995; Shawber et al., 1996). In parallel, we generated a LV encoding a luciferase gene driven by a mutant form of the Hes 1 promoter that lacks the two CBF-1 binding sites (mut-Hes1-LVLuc) (Berechid et al., 2002) or mutated $4 \times \mathrm{CBF}-1$ response element (mut-4 $\times$ CBF1RE-LV-Luc), to establish that the Hes1 promoter or $4 \times \mathrm{CBF}-1$ reporter activities were specific to Notch/ CBF-1 signaling. The efficacy of the Hes1 reporter constructs in measuring Notch/CBF-1 signaling were tested in wild-type $\left(\mathrm{PS}^{+/+}\right.$) or PS-deficient (PS ${ }^{-/-}$) fibroblasts (for details, see sup-
B

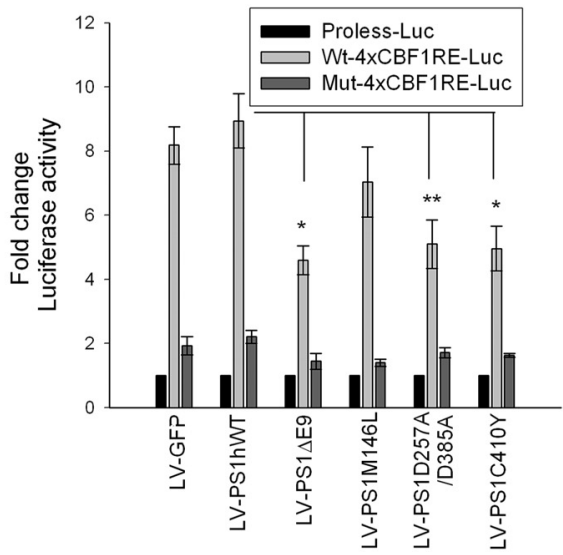

tal material).

Single cell suspensions of cultured NPCs derived from 2-month-old adult nontransgenic mice were transduced with LV encoding either the WT-Hes1-LV-luc or Proless-Luc transcriptional reporters at equal titers. After $7 \mathrm{~d}$, the cultures were reinfected with LV-GFP, LV-PS1hWT or LV-PS1 mutants at an MOI of 30 . The cells were lysed and luciferase activity was quantified $7 \mathrm{~d}$ after transduction. An increase of 6.4-, 6.8-, 4.9-, 5.4-, 5.2- and 3.8-fold in HES1-promoter activity over Proless-Luc reporter activity was detected in cultures transduced with LV-GFP, LVPS1hWT, LV-PS1AE9, LV-PS1M146L, LV-PS1C410Y or LV encoding the catalytically inactive PS1D257A/D385A PS1 polypeptide (Wolfe et al., 1999) (Fig. 5A). It is important to note that in comparison with NPCs transduced with LV-GFP or LVPS1hWT, a significant reduction in endogenous Notch/CBF-1dependent Hes1-promoter transactivation was observed in cultures transduced with LV-PS1 $1 \mathrm{E} 9$, LV-PS1C410Y, or LVPS1D257A/D385A. Under similar experimental conditions, NPCs were transduced with $\mathrm{LV}$ encoding the $4 \times \mathrm{CBF} 1$ response element, a standard reporter that exhibits higher sensitivity in measuring endogenous Notch/CBF-1 signaling (Shawber et al., 1996). In NPCs transduced with LV-GFP or LV-PS1hWT, we observed an 8.1and 8.9-fold increase in Wt-4 $\times$ CBF1RE-LV-Luc activity and only a 1.9 - and 2.2 -fold increase in mut- $4 \times$ CBF1RE-LV-Luc reporter activity compared with the Proless-Luc reporter activity, respectively. However, in NPCs transduced with LV-PS1 $1 \mathrm{E}$, LV-PS1M146L, LV-PS1C410Y, or LV-PS1D257A/D385A, the wild-type $4 \times \mathrm{CBF} 1$ response element activity was diminished to 4.5-, 7-, 5.1- and 4.9-fold, respectively, compared with the minimal Proless-Luc reporter activity (Fig. 5B). In each of these cultures, a maximum of 2 or lower-fold increase in mutant $4 \times \mathrm{CBF} 1$ response element activity was detected over the Proless-Luc promoter reporter activity, suggesting that our observed increases in $4 \times$ CBF1RE-LV-Luc activity in cells expressing PS1 or PS1 mutants was specific to Notch/CBF-1 signaling. It is intriguing to observe that the PS1 $\triangle \mathrm{E} 9$ and PS1C410Y variants that exhibited severely impaired self-renewal (Fig. $1 E$ ) and maximally altered differentiation pattern (Fig. 2) of NPCs were also the polypeptides that significantly diminished both the Hes1-promoter and 

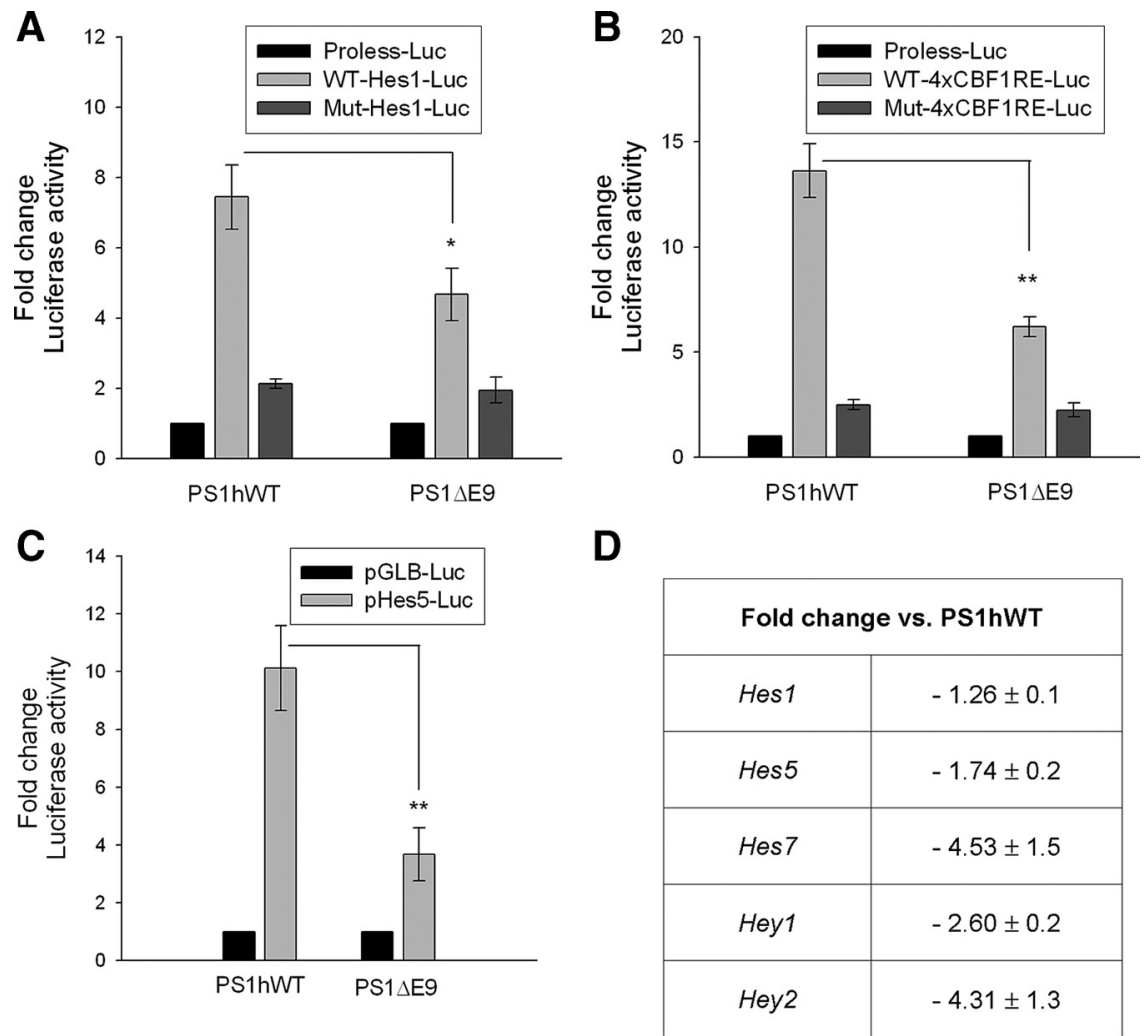

Figure 6. Notch/CBF-1 signaling in NPCs derived from postnatal SVZ of PS1 1 E9 transgenic mice. $\boldsymbol{A}, \boldsymbol{B}$, Fold change in firefly luciferase activity in SVZ NPCs derived from PS1hWT or PS1 $\Delta$ E9 transgenic mice, transduced with either Wt-Hes1-LV-Luc, mutHes1-LV-Luc, Wt-4XCBF1RE-LV-Luc or Mut-4×CBF1RE-LV-Luc over Proless-Luc reporter lentivirus. NPC cultures were established from a minimum of 3 animals per group and pooled before the assay. $N=3$, performed in duplicate; ${ }^{*} p<0.05$; ${ }^{* *} p<0.01$. C, Fold change in firefly luciferase activity in SVZ NPCs derived from PS1hWT or PS1 $\Delta$ E9 transgenic mice electroporated with either Hes5-promoter luciferase or promoterless luciferase construct. NPC cultures were established from a minimum of 3 animals per group. Firefly reporter activity was normalized to Renilla luciferase activity across each sample and represented as fold activation over the level observed with promoterless luciferase reporter. $N=3$, performed in triplicate; ${ }^{* *} p<0.01$. D, Table summarizes the fold changes observed in Hes1, Hes5, Hes7, Hey1 and Hey2 gene transcripts in PS1 1 E9 adult SVZ NPCs relative to their levels detected in PS1hWT NPCs. Data represent $\mathrm{m} \pm \mathrm{SEM}$ of $C_{\mathrm{t}}$ values obtained from three independent quantitative real time RT-PCR experiments on template prepared from NPCs cultured from a minimum of $N=4$ animals per group.

$4 \times$ CBF1RE-based Notch reporter activities (Fig. $5 A, B$ ). Furthermore, the reduction in wild-type $4 \times \mathrm{CBF} 1$ response element activity observed in LV-PS1 $\Delta$ E9- and LV-PS1C410Y-transduced NPCs were comparable to the levels observed in cells transduced with the LV-PS1D257A/D385A, findings which strongly suggest that expression of the PS1 variants leads to partial reductions or loss in PS-dependent $\gamma$-secretase processing of the Notch substrate.

\section{Endogenous Notch/CBF-1 signaling is impaired in adult SVZ} NPCs derived from PS1 $\triangle \mathrm{E} 9$ transgenic mice

We then assayed endogenous levels of Notch/CBF-1 signaling in NPCs established from the SVZ of 2-month-old mice expressing PS1hWT or PS1 $\Delta \mathrm{E} 9$ using both the Hes1-promoter and $4 \times \mathrm{CBF} 1$ response element reporters. In comparison with cells transduced with minimal CMV reporter carrying LV, a 7.4-fold increase in luciferase activity was detected in Wt-Hes1-LV-Luc-transduced PS1hWT NPCs (Fig. 6A). Strikingly, under similar conditions, only a 4.6-fold increase in Hes1 promoter reporter activity was observed in NPCs expressing the PS1 $\Delta \mathrm{E} 9$ variant. Likewise, 13.6and 6.2-fold increase in luciferase activity was detected in PS1hWT and PS1 1 E9 NPCs transduced with Wt-4×CBF1RELV-Luc, respectively compared with Proless-Luc activity (Fig.
$6 B)$. In either of these assays, mutant Hes1-promoter or mutant $4 \times \mathrm{CBF} 1$ response element activities were minimal and no striking changes were observed. In summary, an overall significant decrease of $\sim 1.5$-fold in Hes 1 promoter activity (Fig. $6 A ; p<0.05)$ and $\sim 2.1$-fold $4 \times C B F 1$ response element activity (Fig. $6 B ; p<0.01$ ) was observed in adult SVZ derived PS1 $\Delta \mathrm{E} 9$ compared with PS1hWT NPCs.

In addition to Hes1, other Notch-responsive, Hes family genes, including Hes3 and Hes5 play a role in neural progenitor fate determination during early development and in postnatal brain neurogenic stem niches (Ohtsuka et al., 1999, 2006; Hatakeyama et al., 2004; AndroutsellisTheotokis et al., 2006). In this regard, we chose to measure Notch/CBF-1 signaling in adult SVZ derived PS1hWT and PS1 $\Delta \mathrm{E} 9$ NPCs following electroporation of a reporter construct that contains a DNA segment encompassing -800 to +73 bp of the upstream regulatory region of mammalian Hes5 gene fused to sequences encoding luciferase (Takebayashi et al., 1995; Ohtsuka et al., 1999). Seven days after electroporation, the Hes5-promoter reporter showed an $\sim 10.1$ - and 3.6-fold increase in activity, respectively, compared with a promoterless minimal CMV reporter in PS1hWT and PS1 1 E9 NPCs (Fig. 6C). Thus, in comparison with PS1hWT NPCs, the Notch/CBF1-dependent Hes5-promoter activity was significantly diminished by $\sim 2.75$-fold in PS1 $\Delta$ E9 NPCs (Fig. $6 C$; $p<0.01$ ). Extending these observations, we used q-PCR assays to compare the transcript levels of Hes1, Hes5, Hes7, Hey1 and Hey2, the well established candidate target genes of the mammalian Notch pathway (Hatakeyama et al., 2004; Yu et al., 2008) in NPCs derived from the SVZ of adult PS1hWT or PS1 $\Delta$ E9 mice (see supplemental Fig. 3B, available at www.jneurosci.org as supplemental material). These studies revealed that transcripts encoding Hes1 were moderately reduced by $\sim 1.26$-fold in NPCs expressing PS1 1 E9 compared with PS1hWT (Fig. 6D). Remarkably, the transcripts levels of Hes5, Hes7, Heyl and Hey2 were strongly reduced by 1.74-, 4.53-, 2.6- and 4.31-fold, respectively, in PS1 1 E9 NPCs. Together, these results are in line with the findings observed with the CBF-1 reporter assays and provide additional evidence that CBF-1dependent, endogenous Notch signaling is diminished in NPCs derived from PS1 $\Delta \mathrm{E} 9$ transgenic mice.

Ectopic constitutive activation of Notch signaling restores self-renewal and multilineage differentiation defects in SVZ NPCs derived from PS1 $1 \mathrm{E} 9$ transgenic mice

To unambiguously establish that defective Notch signaling underlies the self-renewal and multilineage differentiation defects observed in adult SVZ-derived NPCs expressing PS1 $\Delta$ E9, it was essential to test whether these phenotypes could be rescued. For these studies, we chose to ectopically express either truncated, constitutively active NICD or Hes1. To achieve this goal, we generated recombinant lentivirus containing dual promoters that 
A

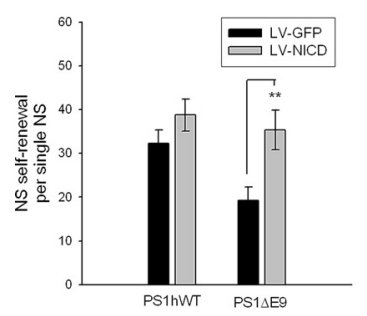

D

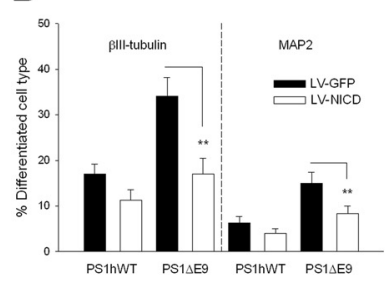

$\mathbf{F}$

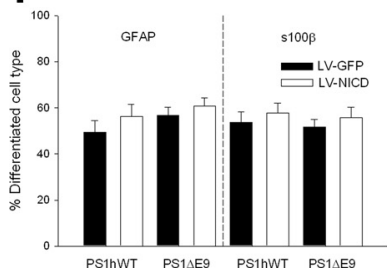

B

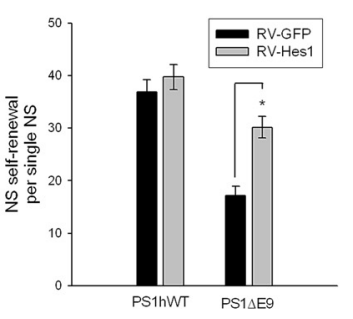

E

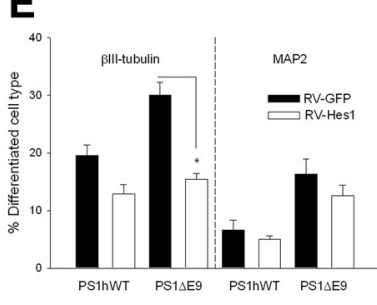

G

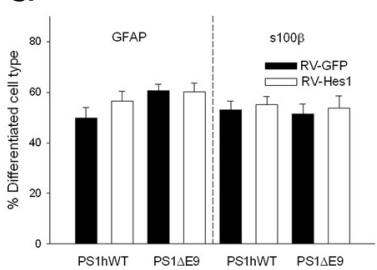

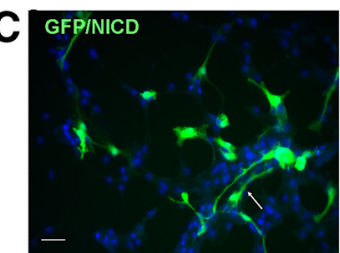
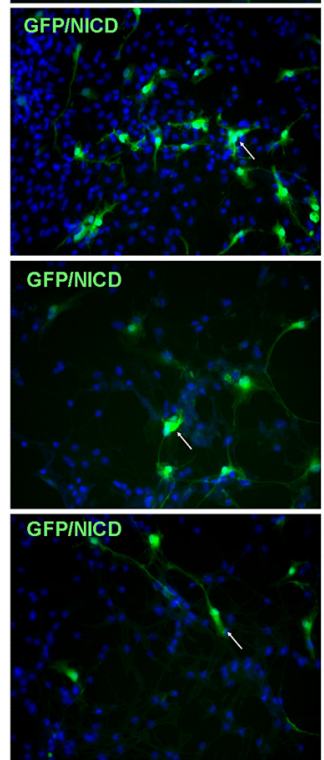
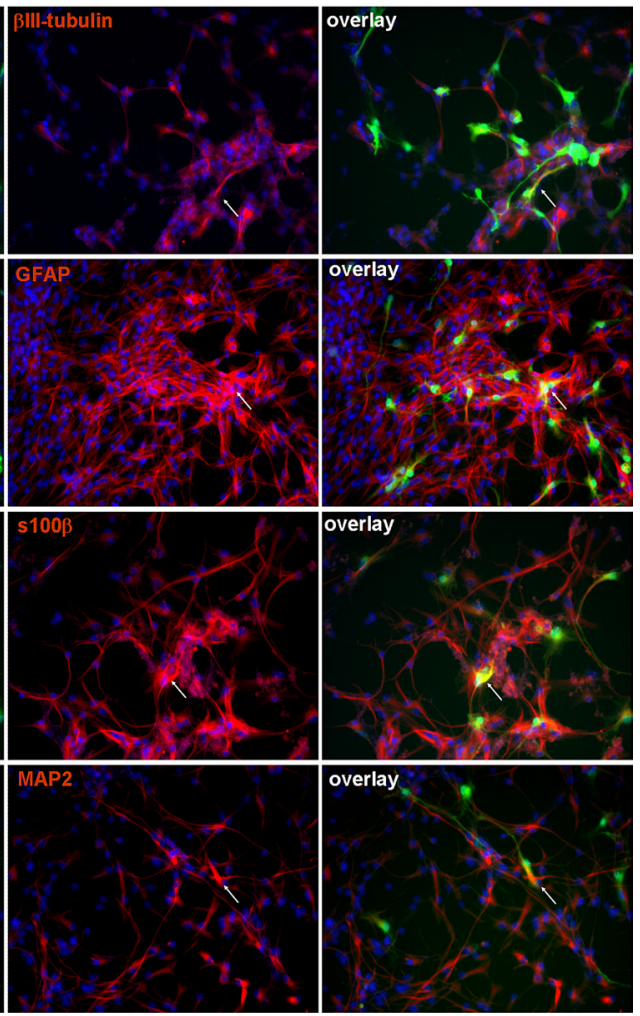

Figure 7. Constitutive Notch activity restores self-renewal and differentiation defects in NPCs derived from postnatal SVZ of PS1 $\Delta$ E9 transgenic mice. $\boldsymbol{A}, \boldsymbol{B}$, Histograms show the number of neurospheres $\geq 40 \mu \mathrm{m}$ in diameter obtained after dissociating a single neurosphere (100 $\mu \mathrm{m}$ in diameter) cultured from SVZ of adult PS1hWT or PS1 $\Delta$ E9 transgenic mice following transduction with lentivirus encoding either GFP or Notch1-ICD $(\boldsymbol{A})$; or retrovirus encoding either GFP or HES1 CDNA $(\boldsymbol{B}) . N=8(\boldsymbol{A})$ or $5(\boldsymbol{B})$, ${ }^{*} p<0.05$; ${ }^{* *} p<0.01$. $\boldsymbol{C}$, Representative photomicrographs reveal the identity of LV-HANotch1-ICD-transduced, GFP ${ }^{+}$NPCs (arrow), differentiated into $\beta$ III-tubulin, GFAP, s100 $\beta$ or MAP2 lineages. Overlay of the respective images are shown on the right of each row. Scale bar, $25 \mu \mathrm{m}$. D-G, Quantification of virus-transduced PS1hWT or PS1 $\Delta$ E9 progenitors differentiated to $\beta$ III-tubulin ${ }^{+}$or MAP2 ${ }^{+}$neuronal $(\boldsymbol{D}, \boldsymbol{E})$ or GFAP ${ }^{+}$astroglial $(\boldsymbol{F}, \boldsymbol{G})$ progeny cell types. Data represent $\mathrm{m} \pm \mathrm{SEM}$ obtained from 6 independent experiments and the differentiated fate was scored by counting a minimum of $100 \mathrm{GFP}{ }^{+}$cells $_{\text {or }} 100 \mathrm{DAPI}{ }^{+}$nuclei that colabeled with neuronal or astrocyte cell fate marker. ${ }^{*} p<0.05 ;{ }^{* *} p<0.01$.

drive expression of either HA-tagged mouse Notch1 intracellular domain lacking the OPA and PEST regions within the intracellular domain (LV-HANotch1-ICD) together with the copGFP as depicted in Figure $1 B$. LV-HANotch1-ICD-infected progenitor derived neurospheres or the differentiated cell types derived from virus infected NPCs were marked by expression of GFP. In addition, we generated retroviruses harboring cDNAs encoding GFP (RV-GFP) or murine myc epitope-tagged Hes1 (RV-HES1). Western blot analysis of detergent extracts from cells transduced with LV-HANotch1-ICD or RV-HES1 confirmed the expression of Notch1-ICD and Hes1, respectively (supplemental Fig. 5, available at www.jneurosci.org as supplemental material). Compared with PS1hWT NPCs that ectopically expressed GFP, we observed only a modest, yet statistically insignificant increase in self-renewal capacity NPCs transduced with either LVHANotch1-ICD (Fig. 7A) or RV-HES1 (Fig. 7B). On the other hand, ectopic expression of Notch1-ICD or Hes1 significantly increased the number of progeny neurospheres generated from PS1 $\triangle \mathrm{E} 9$ NPCs in this self-renewal assay (Fig. $7 A, B$ ). It is interesting to note that the rescue in self-renewal capacity of PS1 $\Delta \mathrm{E} 9$ NPCs, that is comparable to the level observed in PS1hWT NPCs, was only achieved by the expression of Notch1-ICD, but not by expression of Hes1. In differentiation assays (representative images are shown in Fig. 7C), quantitative analysis was performed on cells colabeled with GFP together with $\beta$ III-tubulin, MAP2, GFAP or $s 100 \beta$ (Fig. 7D-G). Expression of either Notch1-ICD or Hes 1 significantly decreased the percentage of $\beta$ III-tubulin ${ }^{+}$lineage committed cells that were otherwise elevated in differenti- ated PS1 $\Delta$ E9 NPCs transduced with LV-GFP (17\% to $11.3 \%$, respectively) (Fig. $7 D$ ) or RV-GFP ( $34 \%$ to $17 \%$, respectively) (Fig. $7 E$ ). The fraction of $\beta$ III-tubulin ${ }^{+}$cells was comparable to the fraction of $\beta$ III-tubulin ${ }^{+}$cells derived from differentiated PS1hWT progenitor cultures that expressed either GFP, Notch1ICD or Hes 1, thus indicating that both Notch1-ICD and Hes 1 are equally competent to restore the altered differentiation pattern of PS1 $\triangle \mathrm{E} 9$ NPCs toward $\beta$ III-tubulin ${ }^{+}$neuronal lineage. Analysis of MAP2 lineage commitment revealed that expression of Notch1-ICD significantly decreased the percentage of MAP2 ${ }^{+}$ lineage committed cells that were otherwise elevated in differentiated PS1 $\triangle$ E9 NPCs transduced with LV-GFP (6.3\% to $4 \%$, respectively) (Fig. $7 D$ ). While a moderate reduction in the percentage of MAP2 ${ }^{+}$lineage committed cells were detected upon ectopic expression of Hes1 expression in PS1 1 E9 NPCs (15\% to $8.3 \%)$, the observed decrease was not significantly less compared with the levels observed with PS1 $\triangle$ E9 NPCs transduced with RVGFP (Fig. 7E).

In contrast to the rescue of neuronal differentiation deficits in PS1 $\mathrm{E} 9$ NPCs upon ectopic expression of Notch1-ICD or Hes1, we observed a modest, yet statistically insignificant increase in the number of $\mathrm{GFAP}^{+}$or $\mathrm{s} 100 \beta^{+}$cells derived from adult PS1hWT or PS1 1 E9 SVZ NPCs following viral transduction of Notch1ICD or Hes1 (Fig. $7 F, G$ ).

\section{Discussion}

Germline and conditional gene deletion studies have revealed that PS1 plays a critical role in embryonic and adult neurogenesis. 
In addition, a series of earlier studies have examined the effects of FAD-linked PS1 mutants on neurogenesis in the adult hippocampus (Wen et al., 2002; Wang et al., 2004; Chevallier et al., 2005) and we have reported that enrichment-induced hippocampal NPC proliferation and neuronal differentiation occurs via non-cell-autonomous mechanisms (Choi et al., 2008). Extending these latter efforts, we have examined the impact of expressing PS1 variants on the cell biology of adult SVZ-derived NPCs, and now offer several important insights. First, adult SVZ-derived NPCs transduced with lentiviruses harboring transgenes encoding the FAD-linked PS1 $\triangle \mathrm{E} 9$ or PS1C410Y variants exhibit a strong inhibition of self-renewal capacity and perturbed differentiation patterns in vitro. These results were confirmed in transgenic mice expressing PS1 $\Delta \mathrm{E} 9$, in which constitutive progenitor proliferation and the steady-state progenitor pool size are diminished in the SVZ. Furthermore, NPCs derived from the SVZ of adult mice expressing the PS1 $\Delta \mathrm{E} 9$ variant exhibit reduced selfrenewal capacity and preferential exit toward the neuronal lineage, alterations consistent with the observed phenotypes in vivo. Notch/CBF-1-responsive, Hes1 and Hes5 promoter/reporter assays and q-PCR analysis of candidate target genes of Notch pathway revealed that Notch signaling is impaired in NPCs expressing the PS1 $1 \mathrm{E} 9$ variant, and thus is relevant for the observed alterations in proliferation, self-renewal and neuronal differentiation. Finally, we show that ectopic expression of constitutively active Notch1-ICD in PS1 $\triangle$ E9 NPCs restores to wild-type levels, the normal self-renewal capacity and differentiation patterns of these progenitors. In the aggregate, these data lead us to conclude that partial reduction in $\mathrm{PS} / \gamma$-secretase-dependent processing of Notch and NICD-mediated signaling, at least in part, are responsible for the observed alterations in proliferation and differentiation of NPCs expressing FAD-linked PS1 variants.

Our results support findings from earlier studies showing that conditional deletion of PSEN1 genes during embryogenesis results in a dramatic depletion of the proliferating progenitor pool (Kim and Shen, 2008), premature exit from the cell cycle and preferential differentiation into $\mathrm{MAP}^{+}{ }^{+}$or $\beta$ III-tubulin ${ }^{+}$neurons; these defects have been attributed to reduced expression of Notch target genes, Hes1 and Hes5 (Shen et al., 1997; Wong et al., 1997; Kim and Shen, 2008) that would otherwise antagonize neuronal differentiation (Iso et al., 2003). Likewise, $P S 1^{+/-}$mice exhibit depleted numbers of adult NPCs, resulting from inhibition of their self-renewal capacity and altered cell cycle (Hitoshi et al., 2002). In this regard, the expression of Notch1, the DSL ligands and Hes family genes have been documented within the SVZ of adult mice (Givogri et al., 2006), and compound genetic reductions of Notch1 and Jagged1 decreases the number of proliferating adult SVZ progenitors, in vivo (Nyfeler et al., 2005). Furthermore, ectopic expression of a constitutively active form of truncated Notch1 in early cortical progenitors of the SVZ at E13.5 prevented the differentiation of these cells toward a neuronal lineage, but instead, promoted proliferation as radial glial progenitor cells (Mizutani and Saito, 2005). These latter findings, when placed in context with the studies in the current report, lead us to offer the conclusion that that the deficits observed in selfrenewal or altered differentiation pattern in SVZ NPCs expressing PS1 variants are the result of impaired Notch signaling.

It is important to note that the results reported herein with respect to the proliferation of SVZ progenitors are not fully consistent with earlier reports showing that expression of FADlinked PS1 variants does not appear to influence the proliferation of SVZ progenitors compared with mice expressing PS1hWT (Wen et al., 2004; Choi et al., 2008). However, it is important to note that in our earlier studies (Choi et al., 2008), we used a single bolus of BrdU and counted labeled cells after $24 \mathrm{~h}$. The apparent discrepancy between our earlier study and the results presented herein can be resolved if one considers the fact that the proliferating capacity of a progenitor pool is determined by the number cells in S-phase, the length of the cell cycle and the proportion of daughter cells that reenter versus exit S-phase (Nowakowski et al., 1989). Given the complexity of cell types in the adult SVZ that are in S-phase, it is highly likely that these cells will be labeled following long-term or multidose injection of BrdU (Merkle et al., 2007) that would easily mask small differences between the groups. In contrast to the studies from Wen et al. (2004) and Choi et al. (2008), we performed a single, low dose $(50 \mathrm{mg} / \mathrm{kg}$ ) BrdU injection, with short $(2 \mathrm{~h})$ duration of labeling before death. The short $2 \mathrm{~h}$ labeling period is ample time for BrdU incorporation into proliferating type $\mathrm{B} 2$ cells and transit amplifying type $\mathrm{C}$ cells, and to a lesser degree, type A cells in the SVZ (Doetsch et al., 1997). Using this approach, we were able to demonstrate that expression of the PS1 $\Delta \mathrm{E} 9$ variant diminishes the steady-state proliferating pool of NPCs, in vivo. Most importantly, our current results obtained from clonogenic neurosphere-forming assay fully corroborate the findings from in vivo BrdU labeling studies.

It has become increasingly evident that that NPC self-renewal and differentiation in the SVZ and hippocampus are regulated by factors secreted by non-neuronal cell types, including microglia (Walton et al., 2006), endothelial cells (Leventhal et al., 1999; Shen et al., 2004) or astrocytes (Song et al., 2002; Lie et al., 2005; Palma et al., 2005; Jiao and Chen, 2008) and that differences in the microenvironment and signaling pathways govern the two adult neurogenic niches (Alvarez-Buylla and Lim, 2004; Jessberger et al., 2008; Moyse et al., 2008). We reported earlier that there were no significant differences in either the percentage of multipotent hippocampal-derived neurospheres on the proliferation rate or self-renewal capacity of isolated hippocampal NPCs or in the multilineage capacity of isolated hippocampal NPCs in in vitro differentiation assays between adult PS1hWT and PS1 $\Delta \mathrm{E} 9$ animals exposed to standard housing conditions (Choi et al., 2008). In contrast to standard housing conditions, we reported that expression of FAD-linked PS1 impairs the proliferation and differentiation of adult hippocampal NPCs following environmental enrichment and factors secreted by microglial cells are at least, in part, responsible for these phenotypes, thus arguing for non-cellautonomous regulation of these processes (Choi et al., 2008). On the other hand, the studies provided in the current report argue for a cell autonomous mechanism by which PS1 variants modulate adult SVZ proliferation or differentiation. In support of this assertion, we find reduced numbers of $\mathrm{BrdU}^{+}$SVZ NPCs in mice expressing the PS1 $\Delta \mathrm{E} 9$ variant in vivo, significant reductions in the percentage of multipotent SVZ-derived PS1 $\Delta$ E9 neurospheres in clonogenic neurosphere assays, reduced self-renewal and slower proliferation rate of isolated SVZ NPCs from PS1 $\Delta$ E9 mice, and altered differentiation patterns of isolated NPCs in in vitro multipotency assay in PS1 $\Delta$ E9 SVZ NPCs.

While the bulk of our data points toward inefficient processing of Notch receptor(s) as the basis of PS1 variant-mediated impairments on NPC self-renewal and differentiation, it is not inconceivable that other signaling pathways may contribute to the observed phenotypes in vivo. In this regard, it has become clear that expression of FAD-linked PS1 variants also impairs $\gamma$-secretase processing of membrane-tethered stubs derived from a variety of type I membrane proteins, including APP, syndecan, DCC, p75 neurotrophin receptor (Jung et al., 2003), ErB4 (Vidal 
et al., 2005) and $N$-cadherin, Delta and Jagged1 (Ikeuchi and Sisodia, 2003), or interfere with the normal turn-over of endogenous $\beta$-catenin (Kang et al., 1999). Future studies to identify the contribution(s) of these signaling pathways and the biochemical substrates by which FAD-linked PS1 mutants alters the biology of the SVZ neurogenic niche during normal aging and in $\mathrm{AD}$ are clearly warranted.

\section{References}

Alvarez-Buylla A, Lim DA (2004) For the long run: maintaining germinal niches in the adult brain. Neuron 41:683-686.

Androutsellis-Theotokis A, Leker RR, Soldner F, Hoeppner DJ, Ravin R, Poser SW, Rueger MA, Bae SK, Kittappa R, McKay RD (2006) Notch signalling regulates stem cell numbers in vitro and in vivo. Nature 442:823-826.

Bentahir M, Nyabi O, Verhamme J, Tolia A, Horré K, Wiltfang J, Esselmann H, De Strooper B (2006) Presenilin clinical mutations can affect gamma-secretase activity by different mechanisms. J Neurochem 96:732742 .

Berechid BE, Kitzmann M, Foltz DR, Roach AH, Seiffert D, Thompson LA, Olson RE, Bernstein A, Donoviel DB, Nye JS (2002) Identification and characterization of presenilin-independent Notch signaling. J Biol Chem 277:8154-8165.

Borchelt DR, Thinakaran G, Eckman CB, Lee MK, Davenport F, Ratovitsky T, Prada CM, Kim G, Seekins S, Yager D, Slunt HH, Wang R, Seeger M, Levey AI, Gandy SE, Copeland NG, Jenkins NA, Price DL, Younkin SG, Sisodia SS (1996) Familial Alzheimer's disease-linked presenilin 1 variants elevate Abeta1-42/1-40 ratio in vitro and in vivo. Neuron 17:1005-1013.

Capowski EE, Schneider BL, Ebert AD, Seehus CR, Szulc J, Zufferey R, Aebischer P, Svendsen CN (2007) Lentiviral vector-mediated genetic modification of human neural progenitor cells for ex vivo gene therapy. J Neurosci Methods 163:338-349.

Chen F, Yang DS, Petanceska S, Yang A, Tandon A, Yu G, Rozmahel R, Ghiso J, Nishimura M, Zhang DM, Kawarai T, Levesque G, Mills J, Levesque L, Song YQ, Rogaeva E, Westaway D, Mount H, Gandy S, St George-Hyslop P, et al. (2000) Carboxyl-terminal fragments of Alzheimer beta-amyloid precursor protein accumulate in restricted and unpredicted intracellular compartments in presenilin 1-deficient cells. J Biol Chem 275:36794-36802.

Chevallier NL, Soriano S, Kang DE, Masliah E, Hu G, Koo EH (2005) Perturbed neurogenesis in the adult hippocampus associated with presenilin-1 A246E mutation. Am J Pathol 167:151-159.

Chiasson BJ, Tropepe V, Morshead CM, van der Kooy D (1999) Adult mammalian forebrain ependymal and subependymal cells demonstrate proliferative potential, but only subependymal cells have neural stem cell characteristics. J Neurosci 19:4462-4471.

Choi SH, Veeraraghavalu K, Lazarov O, Marler S, Ransohoff RM, Ramirez JM, Sisodia SS (2008) Non-cell-autonomous effects of presenilin 1 variants on enrichment-mediated hippocampal progenitor cell proliferation and differentiation. Neuron 59:568-580.

De Strooper B (2003) Aph-1, Pen-2, and nicastrin with presenilin generate an active gamma-secretase complex. Neuron 38:9-12.

Doetsch F, García-Verdugo JM, Alvarez-Buylla A (1997) Cellular composition and three-dimensional organization of the subventricular germinal zone in the adult mammalian brain. J Neurosci 17:5046-5061.

Ferron SR, Andreu-Agullo C, Mira H, Sanchez P, Marques-Torrejon MA, Farinas I (2007) A combined ex/in vivo assay to detect effects of exogenously added factors in neural stem cells. Nat Protoc 2:849-859.

Garcia AD, Doan NB, Imura T, Bush TG, Sofroniew MV (2004) GFAPexpressing progenitors are the principal source of constitutive neurogenesis in adult mouse forebrain. Nat Neurosci 7:1233-1241.

Givogri MI, de Planell M, Galbiati F, Superchi D, Gritti A, Vescovi A, de Vellis J, Bongarzone ER (2006) Notch signaling in astrocytes and neuroblasts of the adult subventricular zone in health and after cortical injury. Dev Neurosci 28:81-91.

Gritti A, Frölichsthal-Schoeller P, Galli R, Parati EA, Cova L, Pagano SF, Bjornson CR, Vescovi AL (1999) Epidermal and fibroblast growth factors behave as mitogenic regulators for a single multipotent stem cell-like population from the subventricular region of the adult mouse forebrain. J Neurosci 19:3287-3297.
Handler M, Yang X, Shen J (2000) Presenilin-1 regulates neuronal differentiation during neurogenesis. Development 127:2593-2606.

Hatakeyama J, Bessho Y, Katoh K, Ookawara S, Fujioka M, Guillemot F, Kageyama R (2004) Hes genes regulate size, shape and histogenesis of the nervous system by control of the timing of neural stem cell differentiation. Development 131:5539-5550.

Hitoshi S, Alexson T, Tropepe V, Donoviel D, Elia AJ, Nye JS, Conlon RA, Mak TW, Bernstein A, van der Kooy D (2002) Notch pathway molecules are essential for the maintenance, but not the generation, of mammalian neural stem cells. Genes Dev 16:846-858.

Ikeuchi T, Sisodia SS (2003) The Notch ligands, Deltal and Jagged2, are substrates for presenilin-dependent "gamma-secretase" cleavage. J Biol Chem 278:7751-7754.

Iso T, Kedes L, Hamamori Y (2003) HES and HERP families: multiple effectors of the Notch signaling pathway. J Cell Physiol 194:237-255.

Jarriault S, Brou C, Logeat F, Schroeter EH, Kopan R, Israel A (1995) Signalling downstream of activated mammalian Notch. Nature 377:355358 .

Jessberger S, Toni N, Clemenson GD Jr, Ray J, Gage FH (2008) Directed differentiation of hippocampal stem/progenitor cells in the adult brain. Nat Neurosci 11:888-893.

Jiao J, Chen DF (2008) Induction of neurogenesis in nonconventional neurogenic regions of the adult central nervous system by niche astrocyteproduced signals. Stem Cells 26:1221-1230.

Jung KM, Tan S, Landman N, Petrova K, Murray S, Lewis R, Kim PK, Kim DS, Ryu SH, Chao MV, Kim TW (2003) Regulated intramembrane proteolysis of the p75 neurotrophin receptor modulates its association with the TrkA receptor. J Biol Chem 278:42161-42169.

Kang DE, Soriano S, Frosch MP, Collins T, Naruse S, Sisodia SS, Leibowitz G, Levine F, Koo EH (1999) Presenilin 1 facilitates the constitutive turnover of beta-catenin: differential activity of Alzheimer's disease-linked PS1 mutants in the beta-catenin-signaling pathway. J Neurosci 19:4229-4237.

Kim SH, Sisodia SS (2005) A sequence within the first transmembrane domain of PEN-2 is critical for PEN-2-mediated endoproteolysis of presenilin 1. J Biol Chem 280:1992-2001.

Kim WY, Shen J (2008) Presenilins are required for maintenance of neural stem cells in the developing brain. Mol Neurodegener 3:2.

Lee MK, Borchelt DR, Kim G, Thinakaran G, Slunt HH, Ratovitski T, Martin LJ, Kittur A, Gandy S, Levey AI, Jenkins N, Copeland N, Price DL, Sisodia SS (1997) Hyperaccumulation of FAD-linked presenilin 1 variants in vivo. Nat Med 3:756-760.

Leventhal C, Rafii S, Rafii D, Shahar A, Goldman SA (1999) Endothelial trophic support of neuronal production and recruitment from the adult mammalian subependyma. Mol Cell Neurosci 13:450-464.

Lie DC, Colamarino SA, Song HJ, Désiré L, Mira H, Consiglio A, Lein ES, Jessberger S, Lansford H, Dearie AR, Gage FH (2005) Wnt signalling regulates adult hippocampal neurogenesis. Nature 437:1370-1375.

Martys-Zage JL, Kim SH, Berechid B, Bingham SJ, Chu S, Sklar J, Nye J, Sisodia SS (2000) Requirement for presenilin 1 in facilitating lagged 2-mediated endoproteolysis and signaling of notch 1. J Mol Neurosci 15:189-204.

Merkle FT, Mirzadeh Z, Alvarez-Buylla A (2007) Mosaic organization of neural stem cells in the adult brain. Science 317:381-384.

Mizutani K, Saito T (2005) Progenitors resume generating neurons after temporary inhibition of neurogenesis by Notch activation in the mammalian cerebral cortex. Development 132:1295-1304.

Molofsky AV, Pardal R, Morrison SJ (2004) Diverse mechanisms regulate stem cell self-renewal. Curr Opin Cell Biol 16:700-707.

Molofsky AV, Slutsky SG, Joseph NM, He S, Pardal R, Krishnamurthy J, Sharpless NE, Morrison SJ (2006) Increasing p16INK4a expression decreases forebrain progenitors and neurogenesis during ageing. Nature 443:448-452.

Morshead CM, Reynolds BA, Craig CG, McBurney MW, Staines WA, Morassutti D, Weiss S, van der Kooy D (1994) Neural stem cells in the adult mammalian forebrain: a relatively quiescent subpopulation of subependymal cells. Neuron 13:1071-1082.

Moyse E, Segura S, Liard O, Mahaut S, Mechawar N (2008) Microenvironmental determinants of adult neural stem cell proliferation and lineage commitment in the healthy and injured central nervous system. Curr Stem Cell Res Ther 3:163-184.

Nakajima M, Shimizu T, Shirasawa T (2000) Notch-1 activation by familial 
Alzheimer's disease (FAD)-linked mutant forms of presenilin-1. J Neurosci Res 62:311-317.

Naldini L, Blömer U, Gage FH, Trono D, Verma IM (1996) Efficient transfer, integration, and sustained long-term expression of the transgene in adult rat brains injected with a lentiviral vector. Proc Natl Acad Sci U S A 93:11382-11388.

Nowakowski RS, Lewin SB, Miller MW (1989) Bromodeoxyuridine immunohistochemical determination of the lengths of the cell cycle and the DNA-synthetic phase for an anatomically defined population. J Neurocytol 18:311-318.

Nyfeler Y, Kirch RD, Mantei N, Leone DP, Radtke F, Suter U, Taylor V (2005) Jagged1 signals in the postnatal subventricular zone are required for neural stem cell self-renewal. EMBO J 24:3504-3515.

Ohtsuka T, Ishibashi M, Gradwohl G, Nakanishi S, Guillemot F, Kageyama R (1999) Hes1 and Hes5 as notch effectors in mammalian neuronal differentiation. EMBO J 18:2196-2207.

Ohtsuka T, Imayoshi I, Shimojo H, Nishi E, Kageyama R, McConnell SK (2006) Visualization of embryonic neural stem cells using Hes promoters in transgenic mice. Mol Cell Neurosci 31:109-122.

Palma V, Lim DA, Dahmane N, Sánchez P, Brionne TC, Herzberg CD, Gitton Y, Carleton A, Alvarez-Buylla A, Ruiz i Altaba A (2005) Sonic hedgehog controls stem cell behavior in the postnatal and adult brain. Development 132:335-344.

Parent A, Linden DJ, Sisodia SS, Borchelt DR (1999) Synaptic transmission and hippocampal long-term potentiation in transgenic mice expressing FAD-linked presenilin 1. Neurobiol Dis 6:56-62.

Pear WS, Nolan GP, Scott ML, Baltimore D (1993) Production of high-titer helper-free retroviruses by transient transfection. Proc Natl Acad Sci U S A 90:8392-8396.

Ray J, Gage FH (2006) Differential properties of adult rat and mouse brainderived neural stem/progenitor cells. Mol Cell Neurosci 31:560-573.

Schroeter EH, Kisslinger JA, Kopan R (1998) Notch-1 signalling requires ligand-induced proteolytic release of intracellular domain. Nature 393: 382-386.

Selkoe DJ (1998) The cell biology of beta-amyloid precursor protein and presenilin in Alzheimer's disease. Trends Cell Biol 8:447-453.

Shawber C, Nofziger D, Hsieh JJ, Lindsell C, Bögler O, Hayward D, Weinmaster G (1996) Notch signaling inhibits muscle cell differentiation through a CBF1-independent pathway. Development 122:3765-3773.

Shen J, Bronson RT, Chen DF, Xia W, Selkoe DJ, Tonegawa S (1997) Skeletal and CNS defects in Presenilin-1-deficient mice. Cell 89:629-639.

Shen Q, Goderie SK, Jin L, Karanth N, Sun Y, Abramova N, Vincent P, Pumiglia K, Temple S (2004) Endothelial cells stimulate self-renewal and expand neurogenesis of neural stem cells. Science 304:1338-1340.

Sisodia SS, St George-Hyslop PH (2002) gamma-Secretase, Notch, Abeta and Alzheimer's disease: where do the presenilins fit in? Nat Rev Neurosci 3:281-290.

Song H, Stevens CF, Gage FH (2002) Astroglia induce neurogenesis from adult neural stem cells. Nature 417:39-44.

Song W, Nadeau P, Yuan M, Yang X, Shen J, Yankner BA (1999) Proteolytic release and nuclear translocation of Notch-1 are induced by presenilin-1 and impaired by pathogenic presenilin-1 mutations. Proc Natl Acad Sci U S A 96:6959-6963.

Takebayashi K, Sasai Y, Sakai Y, Watanabe T, Nakanishi S, Kageyama R (1994) Structure, chromosomal locus, and promoter analysis of the gene encoding the mouse helix-loop-helix factor HES-1. Negative autoregulation through the multiple N box elements. J Biol Chem 269:5150-5156.

Takebayashi K, Akazawa C, Nakanishi S, Kageyama R (1995) Structure and promoter analysis of the gene encoding the mouse helix-loop-helix factor HES-5. Identification of the neural precursor cell-specific promoter element. J Biol Chem 270:1342-1349.
Thinakaran G, Borchelt DR, Lee MK, Slunt HH, Spitzer L, Kim G, Ratovitsky T, Davenport F, Nordstedt C, Seeger M, Hardy J, Levey AI, Gandy SE, Jenkins NA, Copeland NG, Price DL, Sisodia SS (1996) Endoproteolysis of presenilin 1 and accumulation of processed derivatives in vivo. Neuron 17:181-190.

Vanderluit JL, Ferguson KL, Nikoletopoulou V, Parker M, Ruzhynsky V, Alexson T, McNamara SM, Park DS, Rudnicki M, Slack RS (2004) p107 regulates neural precursor cells in the mammalian brain. J Cell Biol 166:853-863.

Vidal GA, Naresh A, Marrero L, Jones FE (2005) Presenilin-dependent gamma-secretase processing regulates multiple ERBB4/HER4 activities. J Biol Chem 280:19777-19783.

Walton NM, Sutter BM, Laywell ED, Levkoff LH, Kearns SM, Marshall GP 2nd, Scheffler B, Steindler DA (2006) Microglia instruct subventricular zone neurogenesis. Glia 54:815-825.

Wang R, Dineley KT, Sweatt JD, Zheng H (2004) Presenilin 1 familial Alzheimer's disease mutation leads to defective associative learning and impaired adult neurogenesis. Neuroscience 126:305-312.

Wen PH, Friedrich VL Jr, Shioi J, Robakis NK, Elder GA (2002) Presenilin-1 is expressed in neural progenitor cells in the hippocampus of adult mice. Neurosci Lett 318:53-56.

Wen PH, Hof PR, Chen X, Gluck K, Austin G, Younkin SG, Younkin LH, DeGasperi R, Gama Sosa MA, Robakis NK, Haroutunian V, Elder GA (2004) The presenilin-1 familial Alzheimer disease mutant P117L impairs neurogenesis in the hippocampus of adult mice. Exp Neurol 188:224-237.

West MJ (1999) Stereological methods for estimating the total number of neurons and synapses: issues of precision and bias. Trends Neurosci 22:51-61.

West MJ, Gundersen HJ (1990) Unbiased stereological estimation of the number of neurons in the human hippocampus. J Comp Neurol 296:1-22.

Wolfe MS, Xia W, Ostaszewski BL, Diehl TS, Kimberly WT, Selkoe DJ (1999) Two transmembrane aspartates in presenilin-1 required for presenilin endoproteolysis and gamma-secretase activity. Nature 398:513-517.

Wong PC, Zheng H, Chen H, Becher MW, Sirinathsinghji DJ, Trumbauer ME, Chen HY, Price DL, Van der Ploeg LH, Sisodia SS (1997) Presenilin 1 is required for Notch1 and DII1 expression in the paraxial mesoderm. Nature 387:288-292.

Wu Y, Liu Y, Levine EM, Rao MS (2003) Hes1 but not Hes5 regulates an astrocyte versus oligodendrocyte fate choice in glial restricted precursors. Dev Dyn 226:675-689.

Xia W, Zhang J, Ostaszewski BL, Kimberly WT, Seubert P, Koo EH, Shen J, Selkoe DJ (1998) Presenilin 1 regulates the processing of beta-amyloid precursor protein C-terminal fragments and the generation of amyloid beta-protein in endoplasmic reticulum and Golgi. Biochemistry 37:1646516471.

Yu X, Zhan X, D’Costa J, Tanavde VM, Ye Z, Peng T, Malehorn MT, Yang X, Civin CI, Cheng L (2003) Lentiviral vectors with two independent internal promoters transfer high-level expression of multiple transgenes to human hematopoietic stem-progenitor cells. Mol Ther 7:827-838.

Yu X, Zou J, Ye Z, Hammond H, Chen G, Tokunaga A, Mali P, Li YM, Civin C, Gaiano N, Cheng L (2008) Notch signaling activation in human embryonic stem cells is required for embryonic, but not trophoblastic, lineage commitment. Cell Stem Cell 2:461-471.

Zaman SH, Parent A, Laskey A, Lee MK, Borchelt DR, Sisodia SS, Malinow R (2000) Enhanced synaptic potentiation in transgenic mice expressing presenilin 1 familial Alzheimer's disease mutation is normalized with a benzodiazepine. Neurobiol Dis 7:54-63. 